\title{
Simulating the global atmospheric black carbon cycle: a revisit to the contribution of aircraft emissions
}

\author{
J. Hendricks ${ }^{1}$, B. Kärcher ${ }^{1}$, A. Döpelheuer ${ }^{2}$, J. Feichter ${ }^{3}$, U. Lohmann ${ }^{4,}$, and D. Baumgardner ${ }^{5}$ \\ ${ }^{1}$ DLR-Institut für Physik der Atmosphäre, Oberpfaffenhofen, Germany \\ ${ }^{2}$ DLR-Institut für Antriebstechnik, Köln, Germany \\ ${ }^{3}$ Max-Planck-Institut für Meteorologie, Hamburg, Germany \\ ${ }^{4}$ Dalhousie University, Halifax, Canada \\ ${ }^{5}$ Centro de Ciencias de la Atmósfera, Universidad Nacional Autonoma de Mexico, Mexico City, Mexico \\ *now at: ETH, Institut für Atmosphäre und Klima, Zürich, Switzerland
}

Received: 19 April 2004 - Published in Atmos. Chem. Phys. Discuss.: 22 June 2004

Revised: 13 October 2004 - Accepted: 1 December 2004 - Published: 10 December 2004

\begin{abstract}
The black carbon (BC) burden of the upper troposphere and lowermost stratosphere (UTLS) is investigated with the general circulation model (GCM) ECHAM4. The special focus is the contribution of aircraft emissions to the UTLS BC loading. Previous studies on the role of aircraft emissions in the global BC cycle either neglect BC sources located at the Earth's surface or simplify the $\mathrm{BC}$ cycle by assuming pre-defined $\mathrm{BC}$ residence times. Here, the global $\mathrm{BC}$ cycle including emissions, transport, and removal is explicitly simulated. The $\mathrm{BC}$ emissions considered include surface sources as well as BC from aviation. This enables a consistent calculation of the relative contribution of aviation to the global atmospheric $\mathrm{BC}$ cycle. As a further extension to the previous studies, the aviation-induced perturbation of the UTLS BC particle number concentration is investigated. The uncertainties associated with the model predictions are evaluated by means of several sensitivity studies. Especially, the sensitivity of the results to different assumptions on the $\mathrm{BC}$ hygroscopic properties is analysed. The simulated UTLS $\mathrm{BC}$ concentrations are compared to in-situ observations. The simulations suggest that the large-scale contribution of aviation to the UTLS BC mass budget typically amounts to only a few percent, even in the most frequented flight regions. The aviation impact far away from these regions is negligible. The simulated aircraft contributions to the UTLS BC particle number concentration are much larger compared to the corresponding mass perturbations. The simulations suggest that aviation can cause large-scale increases in the UTLS BC particle number concentration of more than $30 \%$ in regions highly frequented by aircraft. The relative effect shows a pronounced annual variation with the largest relative aviation impact occurring during winter.
\end{abstract}

Correspondence to: J. Hendricks

(johannes.hendricks@dlr.de)

\section{Introduction}

Anthropogenic black carbon (BC) emissions cause significant perturbations of the global atmospheric aerosol burden (e.g. Penner et al., 1993; Cooke and Wilson, 1996; Liousse et al., 1996; Cooke et al., 1999, 2002). Different atmospheric impacts of $\mathrm{BC}$ aerosols have been discussed. Important climatic effects due to direct impacts on radiation can be expected (e.g. Schult et al., 1997; Haywood and Ramaswamy, 1998; Myhre et al., 1998; Penner et al., 1998; Cooke et al., 1999; Chung and Seinfeld, 2002; Jacobson, 2002). Additionally, indirect climatic effects due to impacts on cloud droplet number concentration and related cloud properties have been considered (e.g. Lohmann et al., 2000). In the upper troposphere and lowermost stratosphere (UTLS), BC particles may be involved in ice cloud formation and may affect the frequency and optical properties of cirrus clouds (e.g. DeMott et al., 1997; Jensen and Toon, 1997; Petzold et al., 1998; Ström and Ohlsson, 1998; Kärcher, 1999; Gierens, 2003; Kärcher and Lohmann, 2003; Lohmann et al., 2004).

Significant amounts of BC aerosols have been observed in the UTLS (e.g. Pueschel et al., 1992; Blake and Kato, 1995; Baumgardner et al., 2003, 2004). Three-dimensional (3-D) model calculations indicate a significant BC loading of the UTLS (e.g. Cooke and Wilson, 1996; Liousse et al., 1996; Cooke et al., 1999, 2002; Koch, 2001; Köhler et al., 2001; Chung and Seinfeld, 2002). Black carbon aerosols are an important combustion product of aircraft engines (e.g. IPCC, 1999). Therefore, it has been debated whether aviation may contribute significantly to the $\mathrm{BC}$ budget of the UTLS region. Danilin et al. (1998) discussed global simulations on the atmospheric dispersion of aircraft fuel tracer emissions performed with different 2-D and 3-D models considering pre-defined tracer lifetimes. From the fuel tracer distributions, the aircraft-induced increase in atmospheric BC

(C) 2004 Author(s). This work is licensed under a Creative Commons License. 
mass loading was derived considering typical $\mathrm{BC}$ emission indices. Rahmes et al. (1998) performed 2-D simulations on the aircraft contribution to the atmospheric BC mass loading including a detailed representation of processes controlling the atmospheric BC cycle. The Danilin et al. (1998) and Rahmes et al. (1998) model studies reveal maximum zonal mean aircraft-induced perturbations in the range of $0.1-1 \mathrm{ng}(\mathrm{BC}) / \mathrm{m}^{3}$ occurring in the northern mid- and high latitude UTLS. However, since the effect of surface BC emissions on the UTLS region was not included in the models, the relative impact of aviation $\mathrm{BC}$ emissions could not be quantified. Detailed knowledge about the total $\mathrm{BC}$ loading of the UTLS or about the contribution of BC from surface sources to the UTLS BC budget is required to evaluate the relative importance of the aviation impact.

Comparing the observational data provided by Pueschel et al. (1992) and Blake and Kato (1995) with the model studies by Danilin et al. (1998) and Rahmes et al. (1998), one finds that the $\mathrm{BC}$ concentrations measured in the northern hemispheric mid- and high latitude UTLS are comparable to the simulated aircraft-induced perturbations. However, recent observations by Baumgardner et al. $(2003,2004)$ reveal that UTLS BC concentrations can be significantly larger than the simulated aviation-induced $\mathrm{BC}$ levels. The observational data currently available is too sparse to provide climatological information on the global BC mass budget. Hence, a robust evaluation of the importance of the simulated aviation impact on the basis of observations is currently not possible.

Information on the UTLS background BC concentrations, attributed to $\mathrm{BC}$ from surface sources, can be gained from other global model studies focused on the atmospheric dispersion of BC from surface emissions (e.g. Cooke and Wilson, 1996; Liousse et al., 1996; Cooke et al., 1999; Koch, 2001; Cooke et al., 2002; Köhler et al., 2001; Chung and Seinfeld, 2002). The UTLS background BC concentrations simulated with the various models can show large differences. Since also the aviation-induced perturbations simulated with the different model approaches discussed by Danilin et al. (1998) and Rahmes et al. (1998) differ significantly, calculations of the relative impact of aviation should be based on a consistent model approach including both surface $\mathrm{BC}$ emissions as well as $\mathrm{BC}$ from aviation. The only study analysing the aviation impact with such a consistent approach was provided by Köhler et al. (2001). The study reveals that the contribution of aviation to the UTLS BC mass loading is small (generally $<1 \%$ ). However, Köhler et al. (2001) stressed that, due to the consideration of pre-defined $\mathrm{BC}$ half-lifetimes in their simulations, a reliable quantification of the aviation impact was not possible. This indicates the need for a more physically-based consistent simulation of the respective contributions of aviation and surface sources to the UTLS BC budget.

In the present study, the impact of aviation on the global $\mathrm{BC}$ budget is quantified by means of simulations with a general circulation model (GCM) considering both 3-D aircraft
$\mathrm{BC}$ emissions as well as $\mathrm{BC}$ from surface sources. The atmospheric $\mathrm{BC}$ cycle including $\mathrm{BC}$ emissions, transport, and removal by wet and dry deposition is simulated explicitly. Aircraft-related BC is treated separately from BC particles resulting from surface emissions to track its atmospheric fate. The previous model studies focused on the atmospheric BC mass loading. Given the potential impact of BC particles on ice cloud formation via heterogeneous nucleation, potential aircraft-induced impacts on the BC particle number concentration in the UTLS region are also investigated here. In Sect. 2, the model is described in detail. Section 3.1 reports on the simulations performed. The major results as well as the uncertainties associated with the model predictions are discussed in Sect. 3.2. The main conclusions are given in Sect. 4.

\section{Model description}

\subsection{General description}

The ECHAM4 GCM (Roeckner et al., 1996) is applied. Standard prognostic variables are vorticity, divergence, temperature, (logarithm of) surface pressure, water vapor and cloud water. The model includes physical parameterizations of radiation, cloud processes, precipitation, convection, diffusion, planetary boundary layer dynamics, land-surface processes as well as gravity wave drag. A spectral transform approach with triangular truncation at zonal wave number 30 (T30) is used. This results in a nominal horizontal resolution of approximately $3.75^{\circ}$ in latitude and longitude. The model domain covers the vertical range from the surface to $10 \mathrm{hPa}$ using 19 vertical layers characterized by a hybrid $\sigma$ p-coordinate system. A semi-implicit leap frog scheme is applied for time integration. A time step $\Delta t$ of $30 \mathrm{~min}$ is used. The horizontal and vertical advection of positive definite quantities like water vapor, cloud water or trace constituents is calculated applying a semi-Lagrangian scheme (Williamson and Rasch, 1994).

\subsection{Aerosols and clouds}

The model version employed here includes explicit predictions of cloud water, cloud ice, as well as cloud droplet and ice crystal number concentration (Lohmann and Roeckner, 1996; Lohmann et al., 1999; Lohmann and Kärcher, 2002). The convective transport of trace constituents is treated according to Brinkop and Sausen (1997). Aerosols are represented as described by Feichter et al. (1996) and Lohmann et al. (1999). The aerosol module treats the atmospheric cycles of sulfate aerosols, carbonaceous particles (organic carbon as well as BC), sea-salt, and mineral dust aerosols. Particle mass concentrations of the respective aerosol types are predicted each time step. Emissions of BC particles, representative of the mid-1980s, are considered as described by Cooke and Wilson (1996) resulting in global BC emission 
rates of 7.96 and $5.98 \mathrm{TgC} \mathrm{yr}^{-1}$ for $\mathrm{BC}$ emissions due to fossil fuel combustion and biomass burning, respectively. The hygroscopic properties of $\mathrm{BC}$ particles are represented according to Cooke et al. (1999) assuming that the BC surface emissions can be characterized as $80 \%$ hydrophobic and $20 \%$ hydrophilic particles and that hydrophobic BC is transformed to hydrophilic $\mathrm{BC}$ according to an exponential decay process showing an e-folding time of $24 \mathrm{~h}$. BC is removed from the atmosphere by wet and dry deposition. Dry deposition rates are calculated according to the surface conditions and the BC hygroscopic properties. Wet deposition occurs via precipitation scavenging of hydrophilic BC. It is assumed that $90 \%$ of the in-cloud hydrophilic BC mass is scavenged by cloud droplets. This is consistent with upper limit in-cloud BC scavenging rates reported in the literature (e.g. Hitzenberger et al., 2001). The BC precipitation flux is then calculated from the in-cloud precipitation formation rate as well as from the efficiencies of below-cloud evaporation and below-cloud scavenging of $\mathrm{BC}$ by rain or snow. In contrast to Lohmann and Kärcher (2002), the mass scavenging efficiency of hydrophilic aerosols by ice is chosen as 5\% instead of $10 \%$. With this modification, the sulfate mass concentrations simulated for the tropopause region are in better agreement with recent observations (Dibb et al., 1998, 2000).

To calculate particle number concentrations from the simulated aerosol mass concentrations, prescribed particle size distributions typical of the respective aerosol type are employed. Lognormal size distributions as described by Köpke et al. (1997) and Hess et al. (1998) are used for each individual aerosol type. Aged BC particles are mostly fractal clusters which can be characterized as long, often multi-connected chains consisting of tiny spherical elements. These spherules are referred to as primary BC particles. Following Köpke et al. (1997), the particle size distribution of the spherules is characterized by a number median diameter of $d=0.0236 \mu \mathrm{m}$ and a geometric standard deviation of $\sigma=2.0$. A specific density of the subspheres of $2.3 \mathrm{~g} \mathrm{~cm}^{-3}$ is assumed. To derive the $\mathrm{BC}$ particle number concentration from the $\mathrm{BC}$ mass concentration, knowledge about the average number of primary particles agglomerated to form an atmospheric $\mathrm{BC}$ particle is required. The number $n$ of primary particles encountered in single atmospheric BC particles can be highly variable even in the upper troposphere and the stratosphere (e.g. Blake and Kato (1995) or Pueschel et al. (2000) for UTLS BC; Strawa et al. (1999) for stratospheric $\mathrm{BC})$. Observational information on $n$ at these altitudes is too sparse to enable robust assumptions on a representative value of $n$. The available measurements suggest that $n$ has an order of magnitude of 10-100. However, small BC particles are underrepresented in these measurements. Hence, we assume that BC particles resulting from surface sources contain 10 primary particles on average. With this assumption the $\mathrm{BC}$ particle number concentration can be derived from the BC mass concentration. The potential consequences of the choice of $n$ for the results of the present study are dis- cussed in Sect. 3.2.5. Aircraft-related BC particles can show different sizes and morphologies compared to $\mathrm{BC}$ related to surface sources. The treatment of aircraft-induced particles in the model is described below.

\subsection{Aircraft BC emissions}

Aircraft BC emissions are calculated here from the global aviation fuel consumption data provided by Schmitt and Brunner (1997) for aircraft activity as occurred in 1992. The data contains information on the global distribution of aircraft fuel use and its annual cycle. A detailed error analysis of global aviation fuel consumption scenarios (IPCC, 1999) reveals that the fuel consumption data used here accounts for only $73 \%$ of the amount of aviation fuel produced in 1992. Hence, aviation fuel consumption may be underrepresented in the present study by up to $20-30 \%$. According to the annual growth rate of aviation fuel consumption (about $4 \%$ per year in the 1984 to 1992 period; IPCC, 1999), the aviation fuel use has increased by about $30 \%$ from the mid-1980s to 1992. Hence, an underestimation as described above would make the aviation fuel consumption data more conformable with the BC surface emissions which are representative of the mid-1980s.

$\mathrm{BC}$ emission rates are derived from the aircraft fuel consumption data using BC emission indices (EIs) typical of commercial aircraft operating in 1992. Emission indices for $\mathrm{BC}$ mass emission rates, $\mathrm{EI}(\mathrm{M})$, have been provided by Döpelheuer (1997) and Petzold et al. (1999). An update of these EIs including an altitudinal variation is used here. Representative EIs were determined for different altitudes by means of a correlation method considering variations in engine type and power conditions (Döpelheuer, 2002). As shown in Fig. 1, the EI(M) decreases from values in the range of $0.08 \mathrm{~g}(\mathrm{BC}) / \mathrm{kg}($ fuel) at the lowest flight levels to values around $0.02 \mathrm{~g}(\mathrm{BC}) / \mathrm{kg}$ (fuel) at $11.5 \mathrm{~km}$ and increases again to $0.08 \mathrm{~g}(\mathrm{BC}) / \mathrm{kg}$ (fuel) at $16 \mathrm{~km}$ to account for supersonic aircraft. The 1992 fleet average $\mathrm{EI}(\mathrm{M})$ amounts to $0.038 \mathrm{~g}(\mathrm{BC}) / \mathrm{kg}($ fuel $)$. The correlation method used to determine these EIs is conform to the measured emission data currently available within a maximum deviation of $10 \%$. Hence the potential uncertainties of the correlation method used to calculate the EIs appear to be too small to result in significant uncertainties of the $\mathrm{BC}$ simulations performed here.

To derive the number concentration of $\mathrm{BC}$ particles resulting from aviation, aircraft exhaust $\mathrm{BC}$ number-to-mass ratios also representative of the 1992 fleet are employed (Döpelheuer, 2002). The number-to-mass ratios, also referred to as particle number EIs or $\mathrm{EI}(\mathrm{N})$, range from $4.8 \times 10^{15}$ particles $/ \mathrm{g}(\mathrm{BC})$ at the surface to around $1.6 \times 10^{16}$ particles/g(BC) at cruise altitude (Fig. 1). The correlation method used to derive the $\mathrm{EI}(\mathrm{N})$ reproduces measured number-to-mass ratios with an accuracy of $\pm 10 \%$. Note, that the EI(N) exceed the number-to-mass ratio assumed for particles related to surface sources (Sect. 2.2) by an order of 


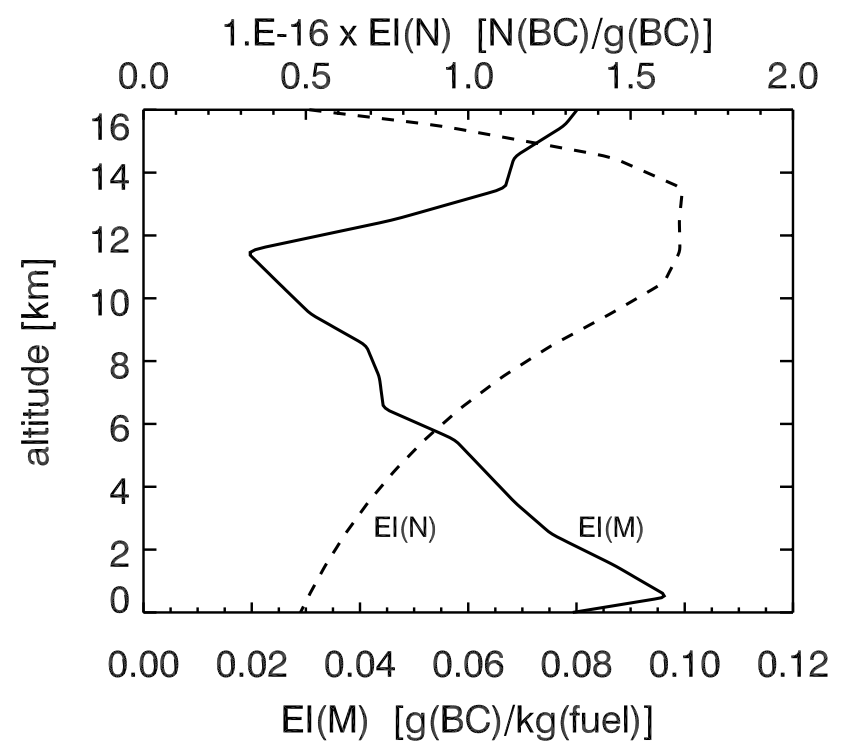

Fig. 1. Vertical profiles of aircraft emission indices for the BC mass (solid) and particle number emission (dashed), representative of the 1992 aircraft fleet. For details see Sect. 2.3 and Döpelheuer (2002).

magnitude (factor 22 at cruise altitude, factor 7 at surface). This is consistent with measurements of particle size distributions of freshly emitted BC. The measurements suggest that BC generated by biomass burning (e.g. Radke et al., 1988; Penner et al., 1998) or fossil fuel combustion (e.g. Maricq et al., 1999) at the Earth's surface show a much larger fraction of large $\mathrm{BC}$ particles (accumulation mode size range; $>\sim 100 \mathrm{~nm}$ ) than BC emitted by aircraft at cruise altitudes which mostly shows particle sizes smaller than $100 \mathrm{~nm}$ (Petzold et al., 1999). This is mainly caused by the more efficient combustion in aircraft engines.

Annual mean vertically integrated BC emissions due to aviation, derived from the aviation fuel consumption data and the EIs described above, are displayed in Fig. 2. The figure reveals that the major fraction of the aircraft $\mathrm{BC}$ emissions occur at northern midlatitudes, especially over North America, the North Atlantic, and Europe. The vertical distribution of the $\mathrm{BC}$ emission rates considered (not shown) reveals that $38 \%$ by mass and $58 \%$ by number of the total aircraft $\mathrm{BC}$ emissions occur at the main flight levels between $10 \mathrm{~km}$ and $12 \mathrm{~km}$ altitude. The seasonal variation considered (not shown) can be large in remote areas but is only small in the main flight regions (mostly within 10\%). The total global emission rate of $\mathrm{BC}$ from aviation amounts to $0.0047 \mathrm{TgC} \mathrm{yr}^{-1}$.

\subsection{Aircraft BC mass concentration}

To quantify the aircraft contribution to the total BC burden in our simulations, aircraft-related BC is numerically represented as an individual trace constituent treated separately from $\mathrm{BC}$ originating from surface sources. The emis-

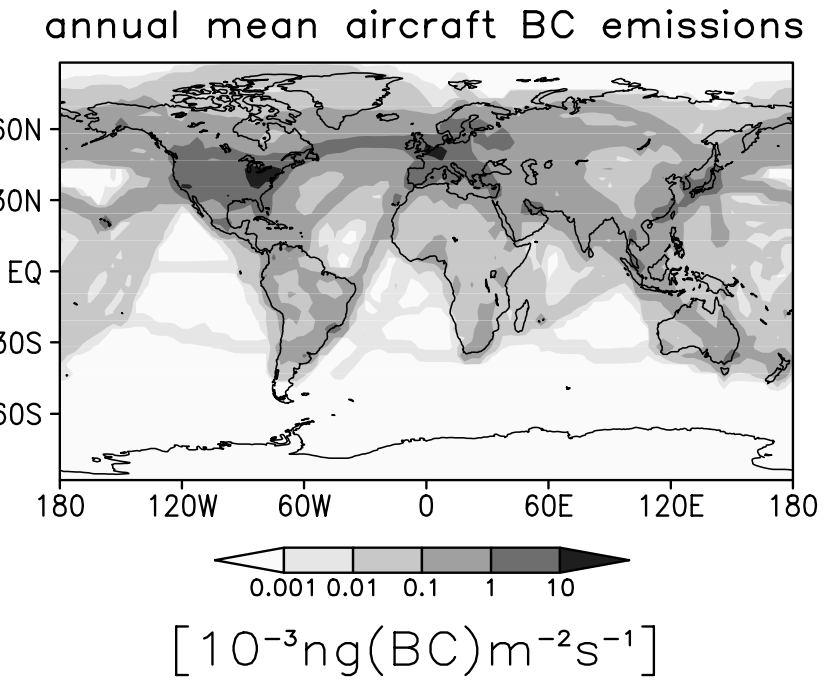

Fig. 2. Annual mean vertically integrated $B C$ emissions due to aviation. The emission rates were derived from aviation fuel consumption data and emission indices for the 1992 global fleet (see Sect. 2.3 for details).

sion rates of $\mathrm{BC}$ from aviation are calculated as described in Sect. 2.3. It is likely that aircraft-generated BC particles become hydrophilic due to activation by chemical processing or deposition of $\mathrm{H}_{2} \mathrm{O}$ and water soluble material in contrails and perhaps also in plumes that do not form contrails (Kärcher, 1999). Hence aircraft-induced BC is generally assumed to be hydrophilic in the present study. Therefore, the mass cycle of BC from aircraft is simulated as described in Sect. 2.2 for hydrophilic BC. The particle number concentration of aviation-induced $\mathrm{BC}$ is treated differently from that of $\mathrm{BC}$ particles originating from surface sources. This will be described in the following.

\subsection{Aircraft BC particle number concentration}

\subsubsection{General remarks}

As mentioned in Sect. 2.2, the number concentration of BC particles from surface sources is derived from the mass concentration assuming a constant number-to-mass ratio. This appears to be justified since BC from surface sources can probably be regarded as aged aerosol in the UTLS characterized by a quasi-invariant size distribution. However, BC from aircraft may possess highly variable number-to-mass ratios ranging from those values which are characteristic of fresh exhaust (Sect. 2.3) to smaller values typical of aged particles. The latter may show a larger degree of agglomeration and may also be mixed with particulate matter not generated by aircraft. Many processes relevant for the ageing of BC from aircraft, for instance, the processing of BC by clouds, are currently not well understood. Many effects of aircraft 
$\mathrm{BC}$ ageing are conceivable, but observational confirmation is lacking. Regarding these uncertainties, a detailed quantification of the BC particle number concentrations was not attempted in this study. Nevertheless, maximum and minimum estimates of the aircraft-induced BC particle number perturbations were performed (Fig. 3).

\subsubsection{Maximum estimate}

A maximum estimate $N_{\text {max }}$ of the number concentration of BC particles from aircraft can be obtained by assuming that the number-to-mass ratio is not affected by particle ageing. Therefore, the high $\mathrm{BC}$ number-to-mass ratio $\mathrm{EI}(\mathrm{N})$ typical for fresh exhaust (Sect. 2.3) applies to the total mass concentration simulated for BC from aviation $M_{\text {BCaircraft }}$ :

$N_{\max }=E I(N) \times M_{B \text { Caircraft }}$

For details on the implementation of Eq. (1), we refer to Sect. 2.5.4.

\subsubsection{Minimum estimate}

A minimum estimate of the number concentration of aircraftgenerated BC particles can be achieved considering only the particle fraction which was not affected by ageing processes reducing the particle number-to-mass ratio. To achieve this, $M_{\text {BCaircraft }}$ is subdivided into "fresh" BC with the mass concentration $M_{f}$ and "aged" $\mathrm{BC}$ with the mass concentration $M_{a}$. "Fresh" BC is generated in the model according to the $\mathrm{BC}$ emission rate. The transformation of "fresh" to "aged" particles is parameterized considering the major ageing processes which potentially reduce the number-tomass ratio. Considering a maximum efficiency of these ageing processes results in a minimum estimate $M_{f, \min }$ of the amount of "fresh" BC from aviation.

To account for the BC ageing caused by aerosol-aerosol interactions in aircraft plumes, we follow the approach by Kärcher and Meilinger (1998) to parameterize aircraft exhaust particle ageing. According to this approach, the dominant aerosol-aerosol interaction leading to changed $\mathrm{BC}$ particle number concentrations in ageing aircraft plumes is the scavenging of $\mathrm{BC}$ particles by larger liquid background aerosols in the accumulation mode size range. This process, which is still relevant after dispersion of the exhaust to large scales, results in liquid particles showing one or several BC immersions. Following the approach by Kärcher and Meilinger (1998), the number of fresh aircraft BC particles (not scavenged by larger aerosols) is estimated here as:

$N_{f}(t+\Delta t)=N_{f}(t) \times \exp \left[-K_{s, b} N_{l}(t) \Delta t\right]$.

Here $N_{f}(t)$ and $N_{l}(t)$ are the number concentrations of fresh aircraft-generated BC particles and accumulation mode background particles, respectively, $K_{s, b}$ is a coagulation coefficient, and $\Delta t$ is the model time step. A coagulation coefficient of $K_{s, b}=10^{-8} \mathrm{~cm}^{3} \mathrm{~s}^{-1}$ was chosen based on Fuchs

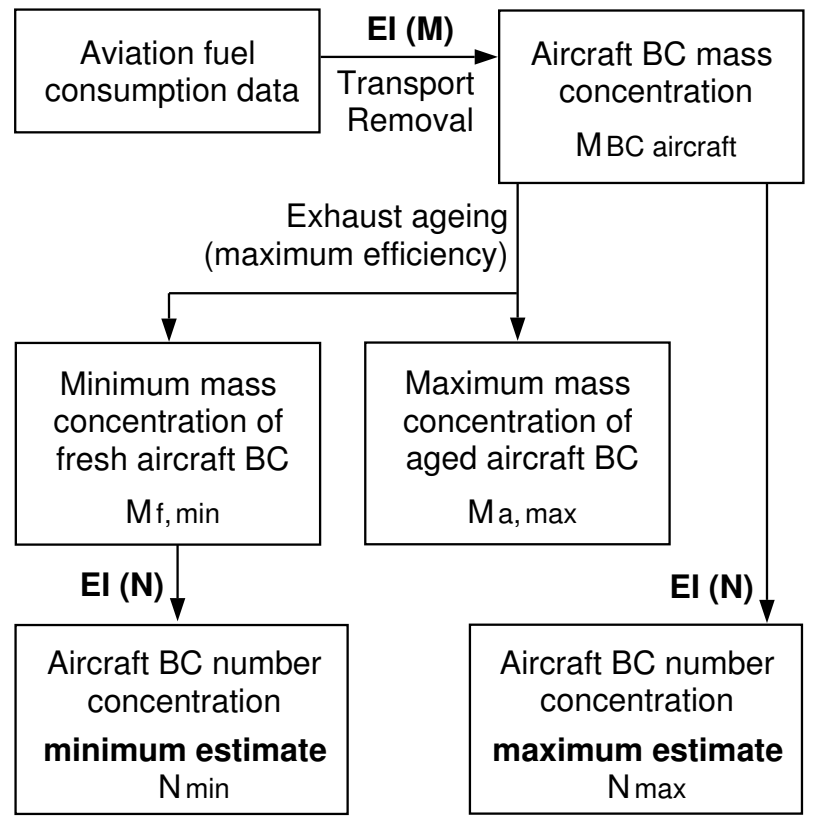

Fig. 3. Flow chart of the approach to obtain minimum and maximum estimates of the number concentration of $\mathrm{BC}$ particles from aircraft. For a detailed description of the method, we refer to Sects. 2.4 and 2.5.

(1964) and on the particle sizes of aircraft-generated BC and background aerosols (Petzold et al., 1999; Schröder et al., 2002). The number concentration $N_{l}(t)$ is calculated from the simulated liquid aerosol mass concentration and observed aerosol size distributions (Schröder et al., 2002). In order to obtain a minimum estimate of the aircraft BC particle number concentration, the maximum possible scavenging rate should be considered. Therefore, $N_{l}$ was increased by a factor of 5 to represent maximum number concentrations of accumulation mode particles observed in the UTLS (Petzold et al., 2002; Minikin et al., 2003).

In order to calculate $M_{f, \min }$, it is assumed that the mass transformation rate scales with the rate of number transformation given by Eq. (2). This assumption is justified since the size distribution of aircraft-generated $\mathrm{BC}$ is dominated by particles in a comparatively narrow size range (e.g. Petzold et al., 1999) and, therefore, impacts of particle size on the scavenging process are of secondary importance.

Ageing of aircraft-induced BC populations may also occur via cloud processing. BC particles from aircraft can be scavenged by cloud droplets or ice crystals. The BC particles can then be removed by precipitation or can be released by re-evaporation of clouds or precipitation. In the case of re-evaporation, the released aircraft $\mathrm{BC}$ particles could be incorporated within larger agglomerates of scavenged particles. Hence, cloud processing potentially results in a reduction of the aircraft $\mathrm{BC}$ particle number-to-mass ratio. In order to perform a minimum estimate of the amount of fresh 
Table 1. Summary of model runs.

\begin{tabular}{ll}
\hline Experiment & Description \\
\hline BASE & standard simulation, $\tau_{B C}=24 \mathrm{~h}$ \\
PHIL & as BASE, but BC generally hydrophilic \\
PHOB & as BASE, but $\tau_{B C}=48 \mathrm{~h}$ \\
NOICE & as BASE, but scavenging of aerosols by cloud \\
& ice is neglected above the $400 \mathrm{hPa}$ level. \\
\hline
\end{tabular}

$\tau_{B C}:=$ e-folding time for transformation of hydrophobic to hydrophilic BC.

aircraft-generated $\mathrm{BC} M_{f, \min }$, the maximum potential impact of cloud processing has to be considered in the model. Therefore, the fresh aircraft BC is transformed into aged BC as soon as significant cloud activity occurs within the air mass carrying the BC particles. The transformation is activated as soon as the cloud liquid water content and the cloud droplet number concentration exceed $5 \mathrm{mg} \mathrm{m}^{-3}$ and $10 \mathrm{~cm}^{-3}$ or as soon as the ice water content and the ice crystal number concentration exceed $0.5 \mathrm{mg} \mathrm{m}^{-3}$ and $0.1 \mathrm{~cm}^{-3}$. These values can be regarded as lower limit thresholds for the occurrence of significant cloud activity (e.g. Pruppacher and Klett, 1997).

Aircraft exhaust BC can also interact with contrail ice which is not considered in the simulations performed here. Exhaust BC particles can be incorporated into contrail ice by serving as heterogeneous ice nuclei or by coagulation scavenging by contrail ice particles (Kärcher, 1999). Incorporation during contrail formation substantially reduces the number concentration of the $\mathrm{BC}$ particles but is unlikely to cause persistent changes of their number-to-mass ratio in the case of short-lived contrails (Schröder et al., 1998). Loss of BC particles due to scavenging by contrail ice becomes relevant only in ageing persistent contrails (Kärcher, 1999). Hence, only in the case of persistent contrails interactions of BC with contrail ice may cause significant reductions of the BC particle number-to-mass ratio. The magnitude of these changes has not yet been quantified by measurements. Persistent contrails form at or above ice saturation. Since the frequency of ice supersaturated regions mostly is smaller than $25 \%$ in the main flight areas (Gierens et al., 2000), the impact of contrail ice particles on $\mathrm{BC}$ from aviation is neglected here.

Since the aircraft BC mass fraction $M_{f, \min }$ obtained as described above is not affected by reductions in numberto-mass ratio, it retained the particle number-to-mass ratio EI(N) typical of the fresh exhaust (Sect. 2.3). Therefore, a minimum estimate $N_{\min }$ of the number concentration of aviation-induced $\mathrm{BC}$ particles can be derived from $M_{f, \min }$ as:

$N_{\min }=E I(N) \times M_{f, \min }$

\subsubsection{Technical realisation}

The mass concentration $M$ of $\mathrm{BC}$ from aircraft can be influenced by $\mathrm{BC}$ emissions occurring at different locations. Therefore, local application of Eqs. (1) and (3) requires a constant $\mathrm{EI}(\mathrm{N})$. In our simulations, $\mathrm{EI}(\mathrm{N})$ varies with altitude and $\mathrm{BC}$ from aviation can experience vertical transport and mixing. To overcome this problem, prognostic equations are solved for $M_{f, \min }, M_{a, \max }$, and the corresponding number concentrations $N_{f, \min }$ and $N_{a, \max } . M_{a, \max }$ is the complementary amount of $M_{f, \min }\left(M_{f, \min }+M_{a, \max }=M_{B \text { Caircraft }}\right)$. $N_{f, \min }$ is equivalent to $N_{\min }$, and $N_{a, \max }$ is the number concentration of aged particles resulting from the assumption that the number-to-mass ratio is unaffected by particle ageing. $N_{a, \max }$ has to be added to $N_{f, \text { min }}$ to obtain $N_{\text {max }}$. The production of $N_{f, \text { min }}$ is calculated from $\operatorname{EI}(\mathrm{N})$ and the aviation BC mass emission rate. Transport and removal of the number concentrations are simulated in analogy to BC mass (Sect. 2.2). Particle ageing is considered according to Sect. 2.5.3.

\section{Model studies}

\subsection{Description of the simulations}

To assess the impact of aviation on the atmospheric BC budget, a set of model experiments (Table 1) was performed using the model framework described in Sect. 2. A simulation with the standard version of the model was performed which is taken as the reference simulation and which will be referred to as the "BASE" simulation.

The relative contribution of aircraft emissions to the $\mathrm{BC}$ budget of the UTLS depends on the corresponding contribution of BC from surface sources which currently is uncertain (Sect. 1). A key uncertainty in simulations of the atmospheric BC cycle is the efficiency of BC removal. Therefore, the atmospheric residence time of $\mathrm{BC}$ can be misrepresented which complicates the evaluation of $\mathrm{BC}$ fluxes from the surface to the UTLS. To investigate the impact of this uncertainty on the UTLS BC budget simulated here, two additional model experiments were performed assuming increased/decreased BC removal efficiencies. This was achieved as follows: $\mathrm{BC}$ is removed from the atmosphere by wet and dry deposition. The efficiency of the simulated BC wet deposition is strongly controlled by the hygroscopic properties of BC which currently are not well understood. In contrast to hydrophobic BC, hydrophilic BC can be scavenged by cloud droplets and ice particles. Therefore the wet deposition efficiency of BC depends on the ratio of hydrophilic to hydrophobic BC. The hygroscopic properties of BC also control its dry deposition efficiency, since hydrophilic BC is deposited more efficiently over wetted surfaces. Hence, the simulated ratio of hydrophilic to hydrophobic $\mathrm{BC}$ is a key parameter controlling the efficiency 
of both wet and dry BC removal processes. In the BASE simulation, $80 \%$ of the $\mathrm{BC}$ emissions from surface sources are assumed as hydrophobic, $20 \%$ as hydrophilic (Sect. 2.2). With an e-folding time of $24 \mathrm{~h}$, hydrophobic BC is assumed to become hydrophilic. In the first sensitivity experiment, $\mathrm{BC}$ particles are generally assumed to be hydrophilic (experiment "PHIL"). Consequently, BC is removed more efficiently compared to the BASE simulation. In a second sensitivity experiment, an e-folding time of $48 \mathrm{~h}$ is assumed for the conversion of hydrophobic into hydrophilic BC (experiment "PHOB"). Therefore BC is removed less efficiently compared to the BASE simulation.

In the global model study by Danilin et al. (1998) on the aviation impact on the UTLS BC load (Sect.1), the impact of wet removal was neglected above $400 \mathrm{hPa}$. In order to make the results of the present study more comparable to the previous study and in order to assess the impact of $\mathrm{BC}$ removal in high clouds, a third sensitivity experiment ("NOICE") was accomplished. Cloud water in the UTLS is mainly present in the ice phase. In the NOICE simulation, scavenging of $\mathrm{BC}$ by ice particles is neglected above the $400 \mathrm{hPa}$ pressure level. The NOICE simulation will be discussed in Sect. 3.2.4 where we compare our results to the simulations performed by Danilin et al. (1998).

The model experiments described above are based on simulations assuming a prescribed annual cycle of sea surface temperatures according to climatological values for the respective month. For each individual experiment, 4-year integrations were performed after a 15-month model spin-up. To provide a robust statistical base for the main conclusions, additional 6 model years were simulated for the BASE experiment. The prolonged (10-year) integration leads to very similar conclusions than the 4-year BASE simulation. The differences in the UTLS BC load occurring between the 4year and the 10-year simulations are generally not larger than a few percent. There is no trend detectable in the UTLS. These statements hold for total BC and for aircraft-induced $\mathrm{BC}$ as well. Hence, with regard to the high computational expenses of the simulations, prolonged integrations were not performed for the PHIL, PHOB and NOICE experiments.

\subsection{Results and discussion}

\subsubsection{Global distribution of UTLS BC mass loading}

Global distributions of the total $\mathrm{BC}$ mass concentration simulated for the $250 \mathrm{hPa}$ pressure level are shown in Fig. 4. The $250 \mathrm{hPa}$ level is chosen since it is located within the main aircraft flight levels. The figure shows results obtained for winter and summer conditions in the BASE, the PHIL and the PHOB experiments.

The $\mathrm{BC}$ concentrations simulated in the BASE simulation for $250 \mathrm{hPa}$ range between about 0.5 and $10 \mathrm{ng} / \mathrm{m}^{3}$. The $\mathrm{BC}$ concentration fields at that pressure level clearly reflect the spatial and temporal variability of the BC surface sources de- scribed, for instance, by Liousse et al. (1996) and Cooke and Wilson (1996). As it will be shown in Sect. 3.2.4, the UTLS $\mathrm{BC}$ mass budget simulated here is dominated by $\mathrm{BC}$ originating from the surface.

The southern hemispheric BC sources are dominated by biomass burning. Due to the strong temporal and spatial variability of biomass burning events, also the $\mathrm{BC}$ concentrations simulated for $250 \mathrm{hPa}$ in the southern hemisphere are characterized by a strong spatial and seasonal variability. At several locations, the southern hemispheric BC fields simulated for spring and autumn conditions (not shown) are very different from the BC fields obtained for the winter and summer seasons.

The BC emissions in the northern hemisphere, especially in the extratropics, are dominated by fossil fuel combustion. The major emission regions of $\mathrm{BC}$ from fossil fuel combustion are North America, Europe, and Southeast Asia. Due to upward transport of BC from the boundary layer, the plumes of these emission regions can clearly be identified at $250 \mathrm{hPa}$ showing a significant spatial shift induced by westerly flows. Since the seasonal variation of the fossil fuel combustion source is small (such variation is not considered here for surface sources), these plumes are the persistent features in the northern midlatitude $\mathrm{BC}$ concentration field at $250 \mathrm{hPa}$ at all seasons. The corresponding concentrations are highest during summer and lowest during winter which can be attributed to the seasonal cycle in vertical transport efficiency.

As in previous global model studies (e.g. Cooke and Wilson, 1996; Cooke et al., 2002), the results obtained in the PHIL and PHOB experiments reveal that the BC concentrations simulated for the UTLS show a marked sensitivity to the prescribed hygroscopic properties of BC. When BC is totally hydrophilic (case PHIL), the simulated UTLS BC concentrations are significantly smaller compared to the BASE case. If a larger fraction of $\mathrm{BC}$ is hydrophobic (case $\mathrm{PHOB}$ ), the UTLS BC concentration increases by factors around 2 compared to the reference experiment. These differences are also reflected in the total atmospheric BC burden which, on average, amounts to $0.213,0.174$ and $0.244 \mathrm{TgC}$ in the BASE, PHIL and PHOB simulations, respectively.

\subsubsection{Comparison to observations}

The sensitivity experiments described above were performed since the current knowledge about the $\mathrm{BC}$ hygroscopicity and $\mathrm{BC}$-cloud interactions is poor. To evaluate which of the experiments is most realistic with regard to UTLS BC, the model results have to be compared to observations. Some data sets are available focusing on BC concentrations in aircraft plumes (e.g. Petzold et al., 1999). Due to the small spatial scales of the plumes, these data cannot be used for evaluating large-scale model output. Only a few data sets of UTLS BC measurements not taken in young aircraft plumes are currently available (Pueschel et al., 1992; Blake and Kato, 1995; Baumgardner et al., 2003, 2004). These measurements were 


\section{total $\mathrm{BC}$ mass, $250 \mathrm{hPa}$}
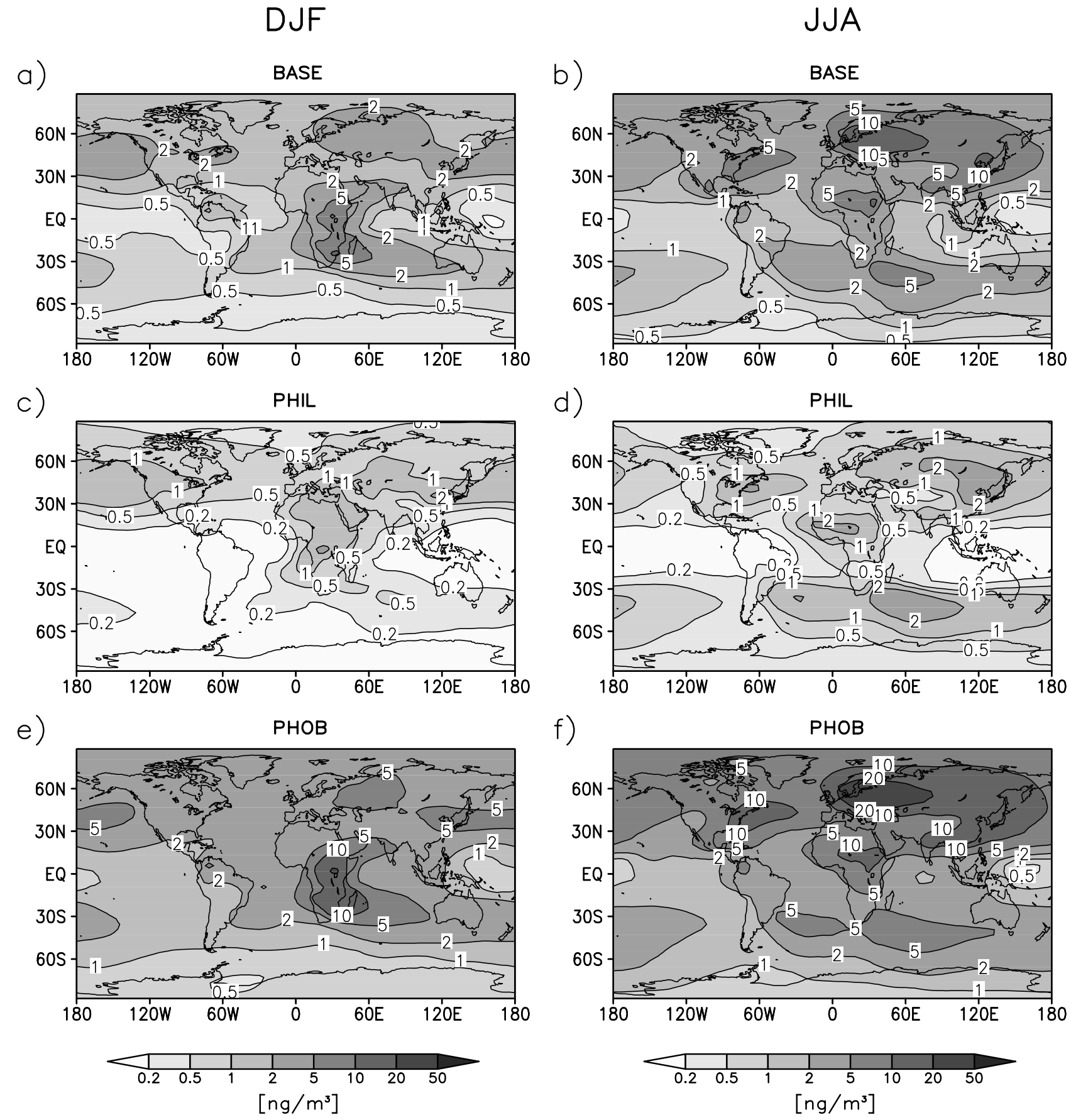

d) PHIL

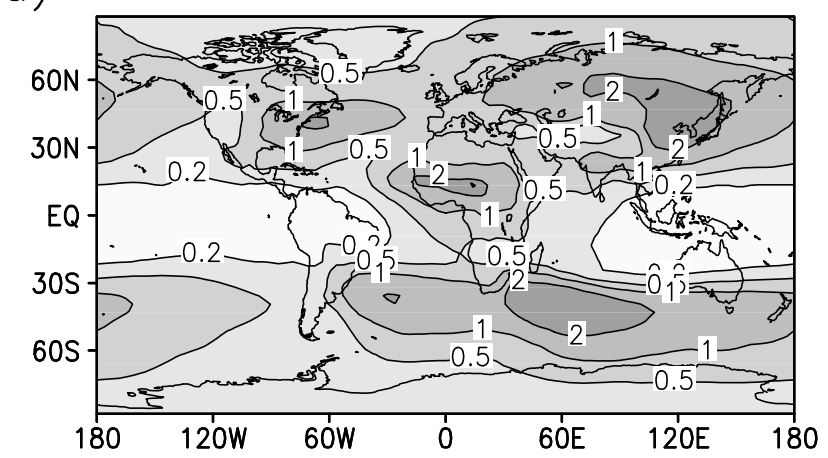

f)

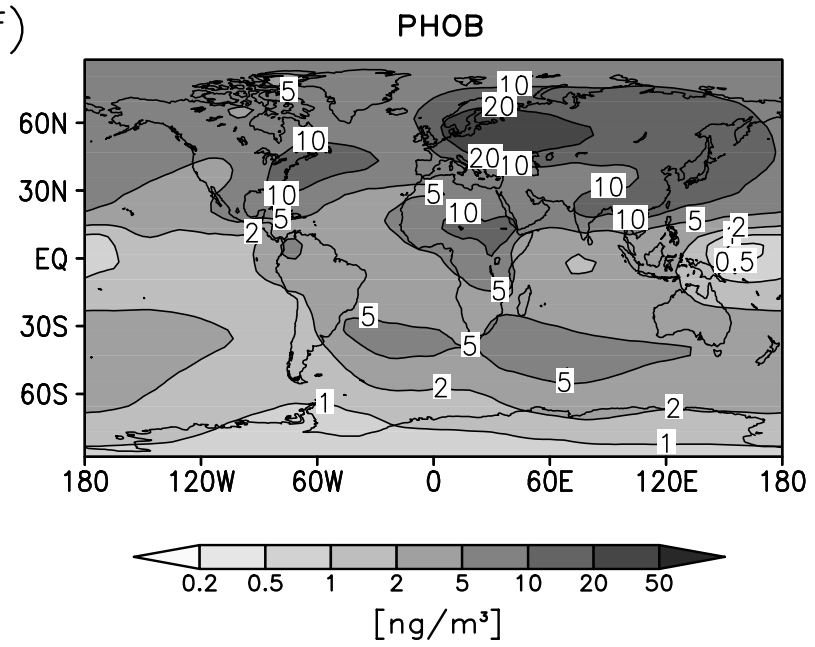

Fig. 4. Total $\mathrm{BC}$ mass concentration $\left(\mathrm{ng} / \mathrm{m}^{3}\right)$ at $250 \mathrm{hPa}$ (main aircraft flight level) during northern hemispheric (NH) winter (left) and summer (right) simulated in the experiments BASE (a, b), PHIL (c, d) and PHOB (e, f). The results represent 4-year averages of the December to February and the June to August periods, respectively.

carried out at a large variety of locations during different episodes. Nevertheless, from a climatological point of view, this data base is too sparse to perform a robust model evaluation. However, given the lack of additional data, we used the measurements to obtain a first guess of the model quality. Additional observations of BC in the UTLS are needed to consolidate the model evaluation. 

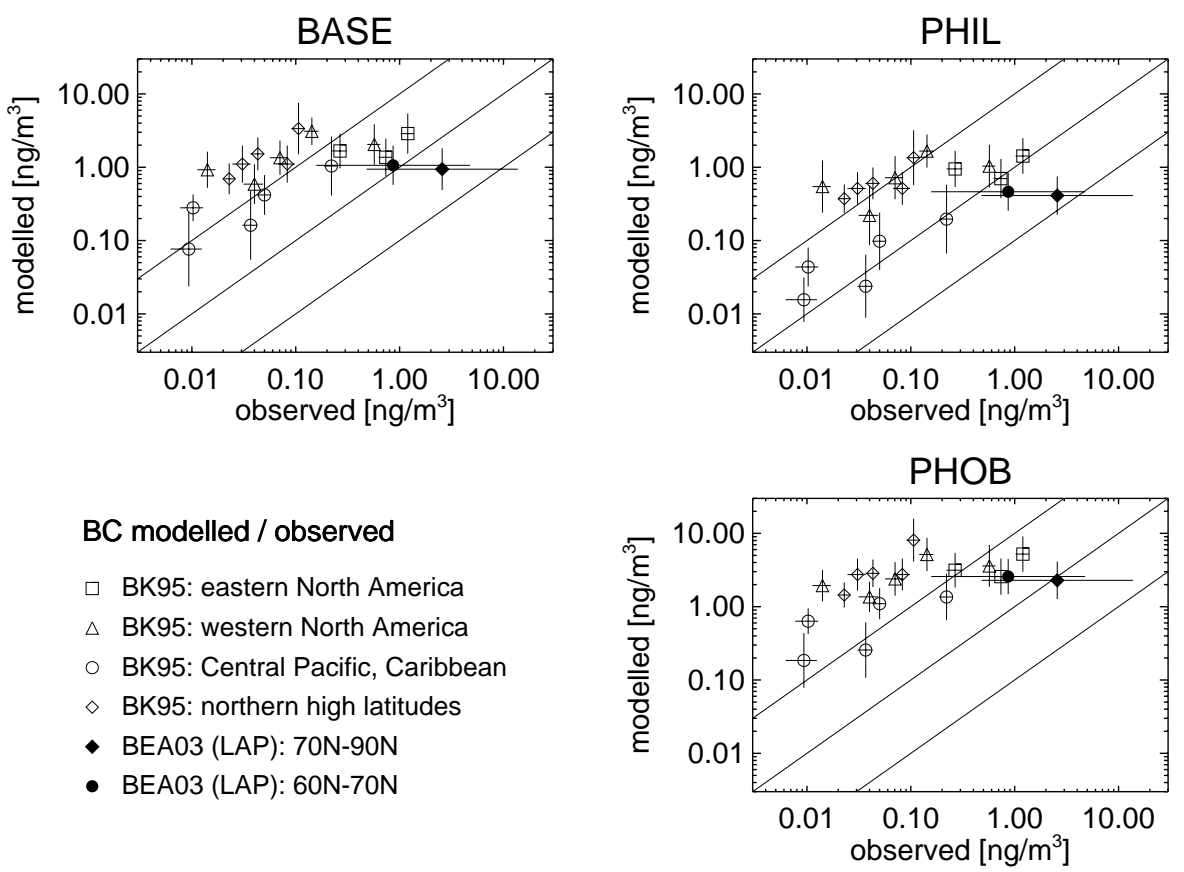

Fig. 5. Comparison of simulated UTLS BC concentrations with in-situ observations of BC (Blake and Kato, 1995, referred to as BK95) and light absorbing particles (LAP) (Baumgardner et al., 2003, 2004, referred to as BEA03). Simulated BC concentrations (ng/ ${ }^{3}$ ) are plotted against observed values. The simulated BC values represent median concentrations and standard deviations (variability of $12-\mathrm{h}$ averages) extracted from the 4-year model output for the geographical positions, altitudes, and months corresponding to the respective observations. Data is shown for the different cases BASE (top left), PHIL (top right) and PHOB (bottom right). Observed values are local values and their uncertainties (BK95) or median values and standard deviations (BEA03). Equity of simulations and observations as well as deviations by one order of magnitude are indicated by diagonal lines. Only measurements performed between 5 and $15 \mathrm{~km}$ altitude were considered. Since the original observational data are normalized to standard (STP) conditions, the data has been adjusted to local conditions. See Sect. 3.2.2 for more details.

Figure 5 shows BC concentrations simulated in the BASE, PHIL and PHOB experiments in comparison to the observational data documented by Blake and Kato (1995) (BK95). This data set includes BC concentrations measured from aircraft in the UTLS during different field campaigns at various locations. Parts of the data were already described by Pueschel et al. (1992). For the comparison, we considered the $\mathrm{BC}$ concentrations of the data points located between 5 and $15 \mathrm{~km}$ altitude as well as the corresponding uncertainties (data taken from Table 1 in BK95 and adjusted from standard to ambient conditions). The analysis method used by BK95 to derive $\mathrm{BC}$ concentrations from wire impactor samples did not take into account the fractal shape of BC particles and did not account for particle bounce. Strawa et al. (1999) showed with a modified method that these simplifications lead to an underestimation of the BC concentration by a factor of 6 on average. Furthermore, Blake and Kato (1995) stressed that small BC particles tend to be underrepresented in the wire impactor samples. Black carbon particles immersed within larger spherical liquid aerosols are generally not detected by the BK95 and the Strawa et al. (1999) method. These uncertainties have to be carefully considered when simulated $\mathrm{BC}$ concentrations are compared to the BK95 data. The un- certainties provided by BK95 (Table 1 in BK95) which are shown in Fig. 5 are probably too low.

The simulated BC concentrations plotted in Fig. 5 were extracted from the model output for the locations, altitudes, and months of the respective measurements. Since the simulated $\mathrm{BC}$ concentrations show an asymmetric frequency distribution (frequency maximum shifted towards small concentrations), median concentrations are analyzed here rather than averages. The median values as well as the corresponding standard deviations displayed in Fig. 5 were derived from 12-hourly averaged model output assuming a lognormal frequency distribution of the $\mathrm{BC}$ concentrations. The resulting concentrations are more representative for the values typically occurring in the simulations than the corresponding averages.

Figure 5 also shows comparisons of the simulations to the recent aircraft measurements of light absorbing particles (LAP) performed by Baumgardner et al. (2003, 2004) (BEA03) in the UTLS over the North Atlantic and the Arctic Sea during a winter episode in 2003. A newly developed single particle soot photometer was applied for these measurements. The uncertainty of this method is reported as $\pm 50 \%$. The lower detection particle size limit is $0.15 \mu \mathrm{m}$. 
The technical details are described by Baumgardner et al. (2003, 2004) and Stephens et al. (2003). The major fraction of the observed LAP particles was found to be BC. However, a large fraction ( $>40 \%)$ was found to be non-BC particles mainly composed of metals. For comparing the data to the simulations, the measured data was averaged over flight segments defined by projecting the flight tracks on the model grid. In analogy to the analysis of the simulations, median LAP concentrations and corresponding standard deviations are then derived from these averages. Therefore, the data was subsumed for the areas between $60^{\circ} \mathrm{N}$ and $70^{\circ} \mathrm{N}$ and north of $70^{\circ} \mathrm{N}$, respectively. Only those measurements taken above $5 \mathrm{~km}$ (all measurements were taken below $15 \mathrm{~km}$ ) were considered. Differences of the resulting BC concentrations shown in Fig. 5 to the values presented by Baumgardner et al. (2004) are due to the use of median concentrations instead of averages and due to the inclusion of data taken in the upper troposphere.

Given the large uncertainties of the BK95 data, a detailed quantitative comparison of these data to the simulations would be not reasonable. Nevertheless, some qualitative features can be compared. The spatial variation of the $\mathrm{BC}$ concentrations simulated in the BASE case is similar to that observed by BK95. Both the measurements and the simulations show a marked contrast between polluted continental and remote marine air masses. The smallest BC concentrations occur over the central Pacific whereas large concentrations are found over eastern North America. The data points over western North America, where continental and marine influences compete, tend to show medium concentrations in the BK95 data as well as in the simulation. This is also the case for the northern high latitude data. Nevertheless, the differences in the $\mathrm{BC}$ concentration occurring between polluted continental and remote areas are more pronounced in the measurements. This possibly reflects that BC immersed within larger liquid aerosol is underrepresented in the BK95 data. Black carbon occurring in remote areas may have been transported over long distances. This implies a large probability that a significant fraction of this BC has been immersed and, therefore, is not detected with the BK95 method.

The $\mathrm{BC}$ concentrations simulated in the BASE experiment are well accordable with the BEA03 data taken north of $70^{\circ} \mathrm{N}$. Taking into account that about $50 \%$ of the LAP is BC, the simulated and observed median $\mathrm{BC}$ concentrations nearly match. Between $60^{\circ} \mathrm{N}$ and $70^{\circ} \mathrm{N}$, the simulated $\mathrm{BC}$ concentrations are similar to the LAP concentrations observed by BEA03. However, the simulated concentrations exceed the observed values after taking into account that only about $50 \%$ of the observed LAP is BC. Nevertheless, within the given variability ranges, the simulations are accordable with the measured values. It should be addressed whether the measurements could be biassed due to the lower detection particle size limit of $0.15 \mu \mathrm{m}$. Observations performed by Neusüß et al. (2000a,b, 2002) and Matta et al. (2003) under a variety of conditions indicate that the $\mathrm{BC}$ mass contained in particles smaller than $0.15 \mu \mathrm{m}$ mostly is small. The contribution of these particles to total $\mathrm{BC}$ was generally below $30 \%$ during the measurements. Hence, the absence of small particles in the observations appears to be of secondary importance for this comparison.

The BC concentrations simulated in the PHIL and PHOB experiments which are also displayed in Fig. 5 show spatial variations quite similar to those simulated in the BASE case. However, the simulated absolute BC loadings show marked differences to the BASE experiment. As already discussed in Sect. 3.2.1, the PHIL and PHOB simulations tend to show smaller and larger concentrations, respectively. When we consider that about $50 \%$ of the LAP is BC, the PHIL experiment is well accordable with the BEA03 measurements taken between $60^{\circ} \mathrm{N}$ and $70^{\circ} \mathrm{N}$ but shows too small concentrations north of $70^{\circ} \mathrm{N}$. Under the same assumption, the PHOB simulation shows too much BC. Hence the BASE simulation appears to be most conformable with the BEA03 data. Given the large uncertainty of the BK95 data, we therefore focus on the BASE case in the assessment of the aviation impact (Sects. 3.2.4 and 3.2.5).

\subsubsection{Comparison to other global model studies}

Comparisons of $\mathrm{BC}$ simulations with the observational data by Blake and Kato (1995) have also been performed in other global model studies (Cooke et al., 1999, 2002; Koch, 2001). As in the simulations performed here, the BC concentrations simulated by Cooke et al. (2002) and Koch (2001) show a similar spatial variation as observed by Blake and Kato (1995). Cooke et al. (1999) focused on altitudinal variations and did not analyse the geographical dependence. Due to the large uncertainties inherent in the measurements, the quality of the UTLS BC concentrations simulated by the different models cannot be evaluated here. Nevertheless, it is worthwhile to compare the UTLS BC concentrations obtained with different global model systems.

As mentioned in Sect. 1, simulations of the UTLS BC load are discussed in a couple of global model studies (Cooke and Wilson, 1996; Liousse et al., 1996; Cooke et al., 1999, 2002; Koch, 2001; Köhler et al., 2001; Chung and Seinfeld, 2002). Only surface emissions were considered in these studies, except for Köhler et al. (2001) who considered both surface sources and aircraft emissions. The UTLS BC concentrations obtained with the different model approaches can show significant deviations. The zonal mean BC concentrations simulated for the pressure range between 300 and $200 \mathrm{hPa}$ in the northern hemisphere vary from values of $1-10 \mathrm{ng} / \mathrm{m}^{3}(\mathrm{Li}-$ ousse et al., 1996, and this study) to values of $10-50 \mathrm{ng} / \mathrm{m}^{3}$ (Cooke and Wilson, 1996; Koch, 2001). The studies by Chung and Seinfeld (2002), Cooke et al. $(1999,2002)$ and Köhler et al. (2001) show intermediate concentrations. The corresponding $\mathrm{BC}$ concentrations in the southern hemisphere 


\section{BC mass contribution from aircraft (BASE), $250 \mathrm{hPa}$}

\section{absolute}

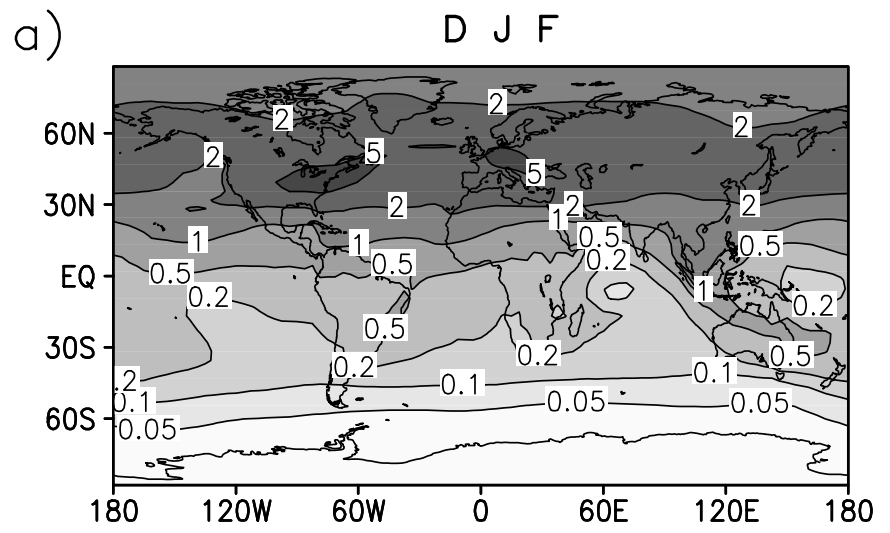

c)
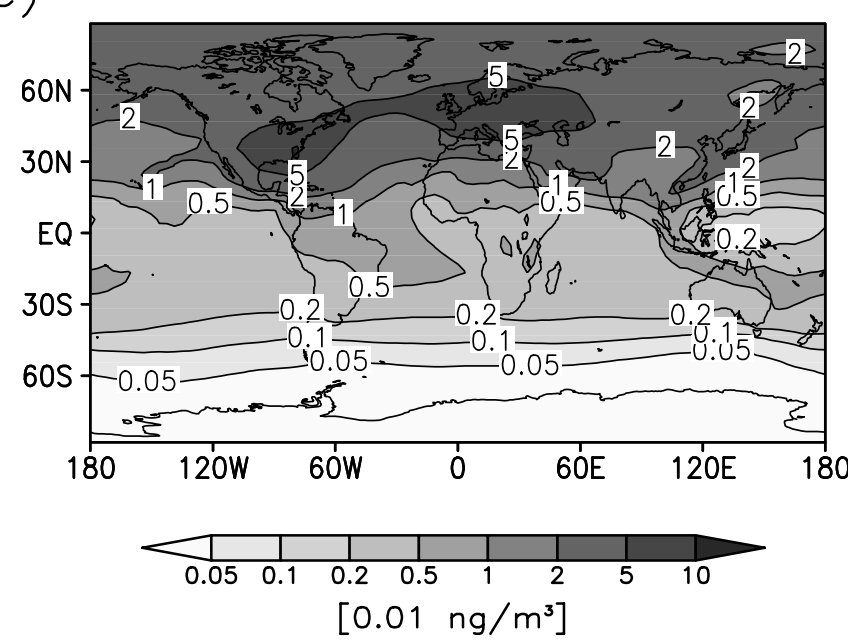

\section{relative}

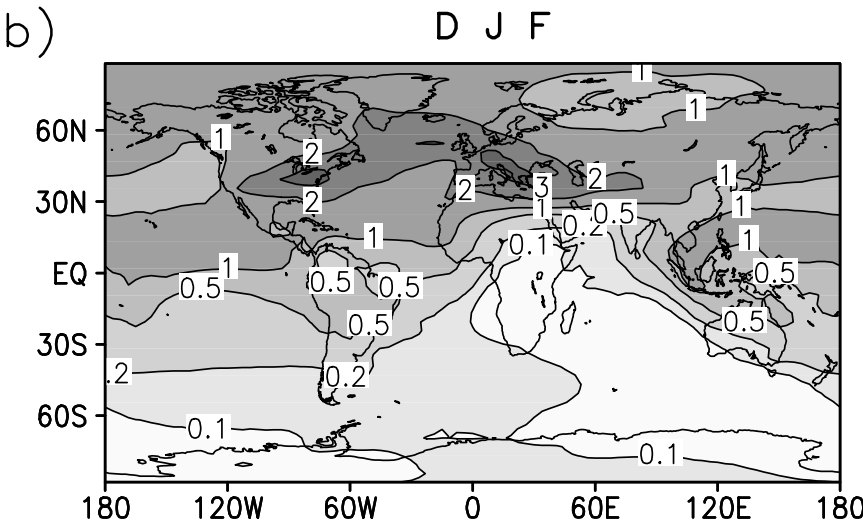

d)

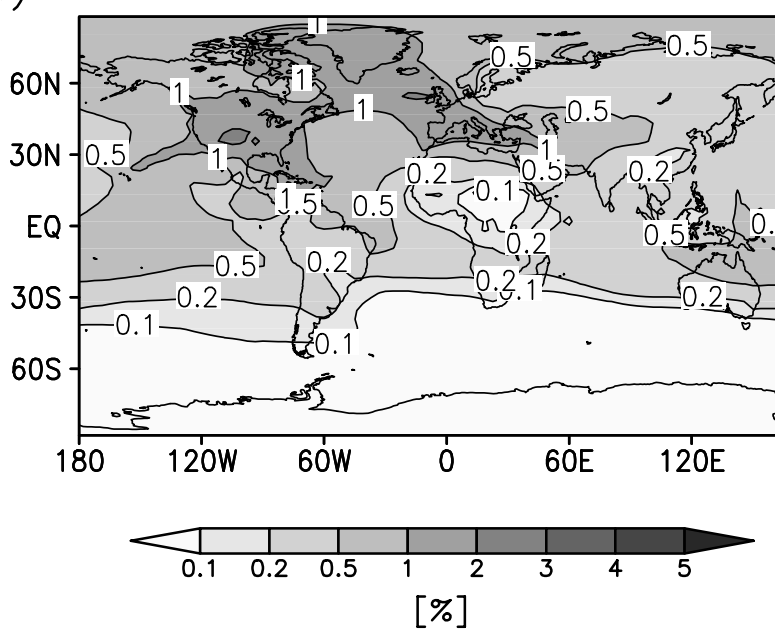

Fig. 6. Contribution of aviation to the $\mathrm{BC}$ mass concentration at $250 \mathrm{hPa}$ (main flight level) during $\mathrm{NH}$ winter (a, b) and summer (c, d) as simulated in the BASE experiment. Absolute contributions $\left(0.01 \mathrm{ng} / \mathrm{m}^{3}\right)(\mathrm{a}, \mathrm{c})$ and relative contributions $(\%$ of total BC mass $)(\mathrm{b}, \mathrm{d})$ are displayed. The results represent 4-year averages of the December to February and the June to August periods, respectively.

are typically an order of magnitude smaller but mostly show similar differences between the various model approaches.

The discrepancies can have manifold reasons. The studies of Cooke et al. (1999) and Cooke et al. (2002) take into account $\mathrm{BC}$ emissions from fossil fuel combustion only which causes marked differences to the other studies especially in the tropics and the southern hemisphere where biomass burning is the dominating $\mathrm{BC}$ source. The simulations by Cooke et al. show comparatively small $\mathrm{BC}$ concentrations in the southern hemispheric UTLS. The other studies include BC from both biomass burning and fossil fuel combustion. Since the total emission rates vary only slightly between these studies, differences in the emission scenarios probably are of secondary importance for the simulated UTLS BC budget. Sensitivity experiments performed in some of the studies demonstrate that the simulated UTLS BC concentrations are very sensitive to the treatment of BC wet removal (see also Sect. 3.2.1). Hence, parts of the deviations described above can probably be attributed to different representations of the $\mathrm{BC}$ hygroscopicity, precipitation scavenging or precipitation itself. The studies by Danilin et al. (1998) and Rogers et al. (2002), where aircraft emission tracer simulations performed with a large set of global models were compared, indicate that also differences in the transport characteristics of 


\section{BC mass (BASE), vertical distribution}
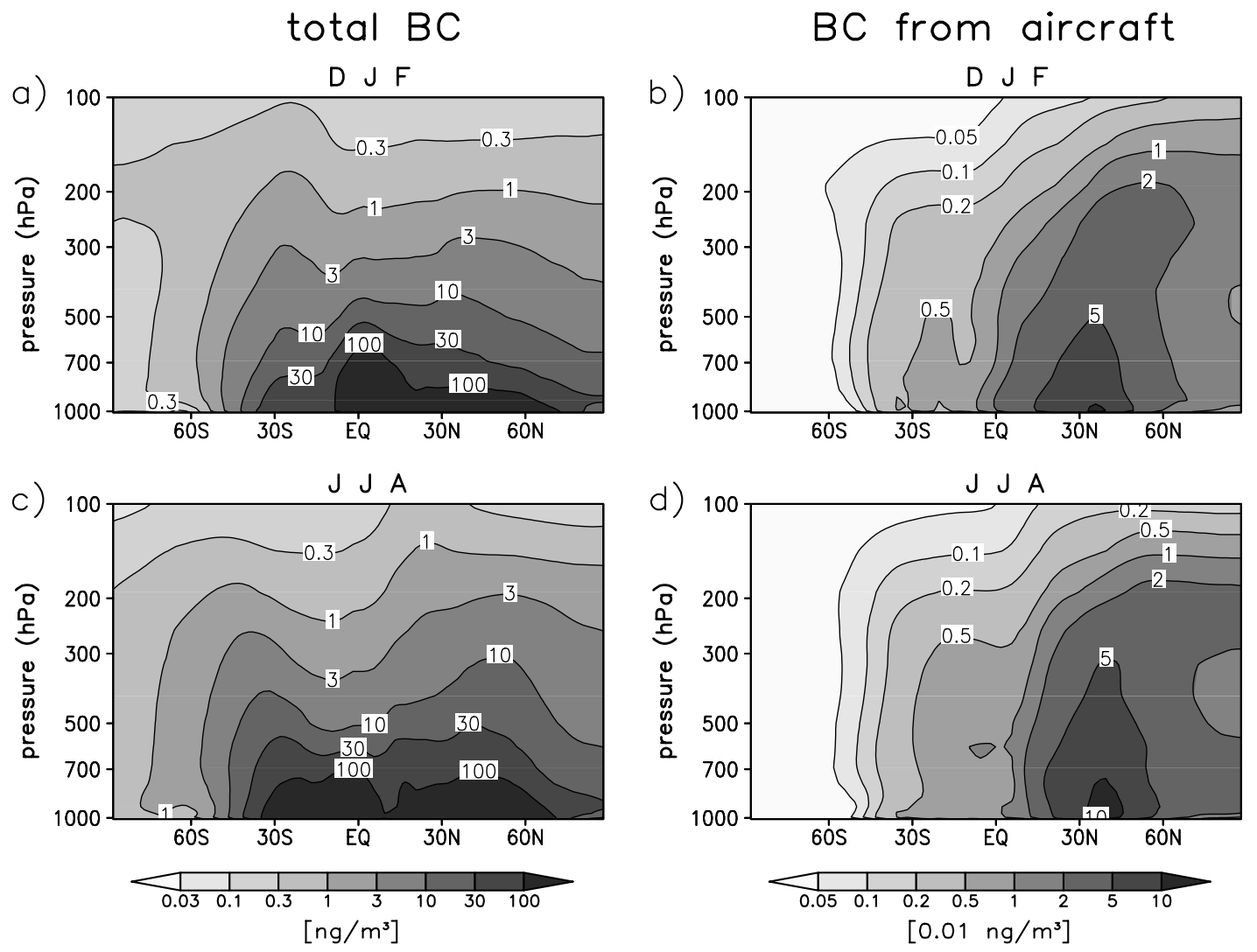

Fig. 7. Left: Vertical distribution of zonal mean total BC mass concentration $\left(\mathrm{ng} / \mathrm{m}^{3}\right)$ during $\mathrm{NH}$ winter (a) and summer (c) simulated in the BASE experiment. Right: Corresponding BC contribution of aviation $\left(0.01 \mathrm{ng} / \mathrm{m}^{3}\right)(\mathbf{b}$, d). The displayed concentrations represent 4 -year averages of the December to February and the June to August periods, respectively.

the models can be very important. Hence, also the transport scheme applied in the present study is a potential source of uncertainty (see also Sect. 3.2.4).

Due to the lack of extensive observations of $\mathrm{BC}$ in the UTLS, it is currently not possible to evaluate the quality of the simulations discussed above. Nevertheless, the UTLS BC concentrations simulated by the different models neglecting aircraft emissions are similar to or even larger than the available observed concentrations. This suggest a very large contribution of BC from surface sources to the UTLS BC budget.

Given the distinct differences in UTLS BC simulated with the different models, absolute contributions of different sources to the atmospheric BC cycle are not necessarily comparable if they were estimated with different models. This implies that a quantitative investigation of the relative impact of aircraft emissions to the atmospheric $\mathrm{BC}$ budget should be based on a consistent model approach including all relevant BC sources. Comparisons of simulations including only the aviation source (Danilin et al., 1998; Rahmes et al., 1998) with the results of other studies focusing on simulations of
$\mathrm{BC}$ from surface sources are not reasonable. In the present study, simulations including both BC from aviation and from surface sources are performed. Estimates of the absolute and relative aviation impacts based on these simulations are discussed below.

\subsubsection{Contribution of aviation to $\mathrm{BC}$ mass loading}

Figure 6 highlights the absolute and relative contribution of $\mathrm{BC}$ from aviation to the $\mathrm{BC}$ mass concentration at $250 \mathrm{hPa}$ (main flight level) as simulated in the BASE case for winter and summer conditions. The amount of $\mathrm{BC}$ resulting from aviation is largest at northern midlatitudes. Maximum contributions of more than $0.05 \mathrm{ng} / \mathrm{m}^{3}$ occur in the main flight areas over North America, the North Atlantic and Europe. The aviation contribution at $250 \mathrm{hPa}$ generally exceeds $0.02 \mathrm{ng} / \mathrm{m}^{3}$ at northern midlatitudes and decreases strongly from the northern to the southern hemisphere. The absolute aviation impact is largest during summer when the inflow from lower layers carrying higher amounts of aircraft BC (Fig. 7) is largest. Similarly to BC from surface sources 


\section{annual mean $B C$ mass, vertical distribution}
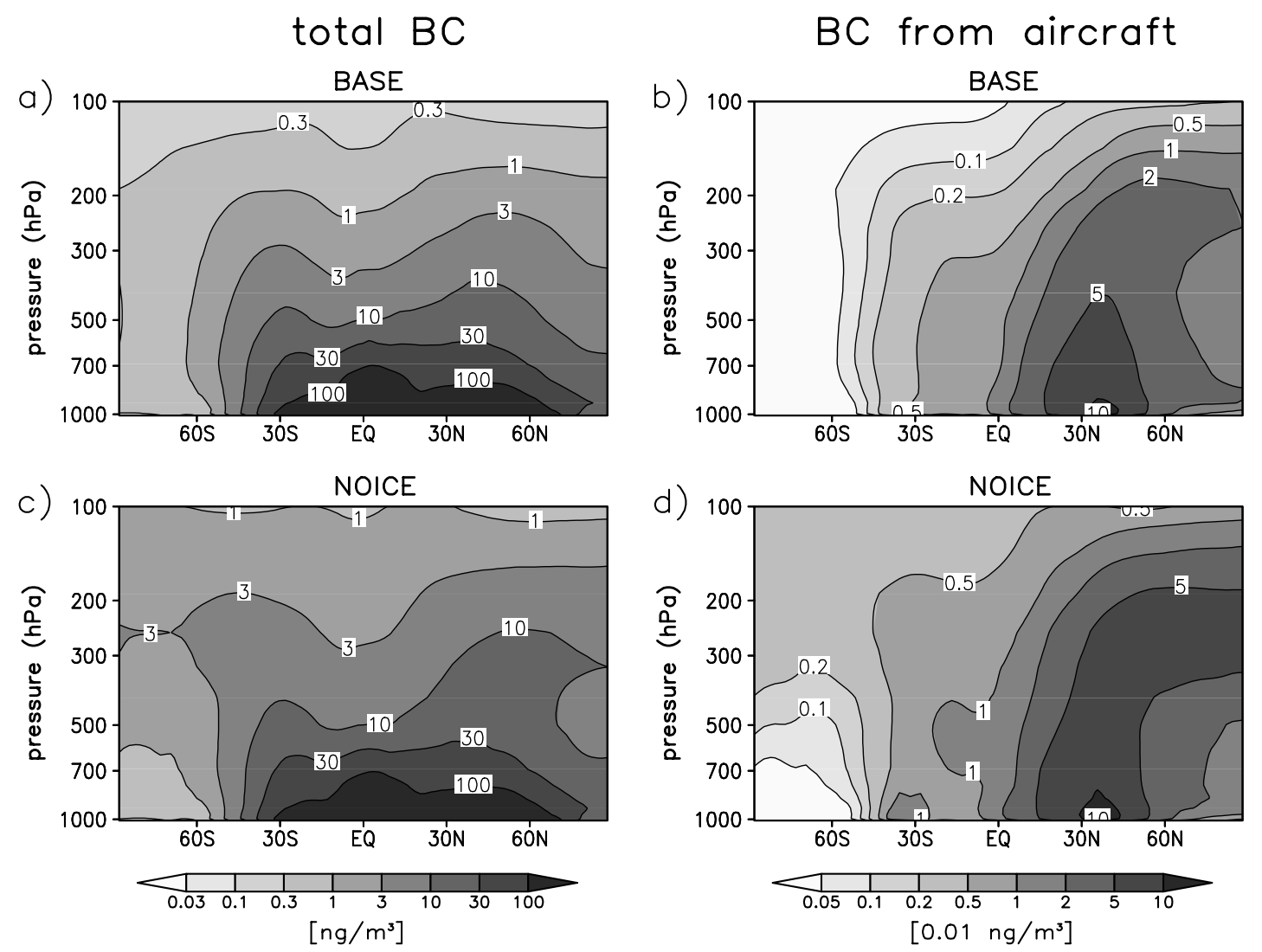

Fig. 8. As Fig. 7, but annual mean BC mass concentrations obtained in the BASE (a, b) and NOICE (c, d) simulations.

(Sect. 3.2.1), BC emitted by aircraft at low altitudes can be transported into the UTLS and can be further dispersed there by efficient westerly flows. Note that the aircraft-induced $\mathrm{BC}$ perturbations simulated for spring and autumn conditions (not shown) exhibit no extraordinary features and fit smoothly in the annual cycle suggested by the results obtained for winter and summer.

Compared to the total $\mathrm{BC}$ mass concentrations present at $250 \mathrm{hPa}$ (Fig. 4), the contribution from aircraft is small. Maximum relative contributions of 2-3\% during winter and 1-2\% during summer are simulated. The aviation-induced perturbations of UTLS BC are clearly smaller than the inter-annual variability of the mass concentration of northern hemispheric UTLS BC originating from the surface (standard deviations of around $0.1-1 \mathrm{ng} / \mathrm{m}^{3}$ in the 10-year BASE simulation). Hence, the simulations reveal that the contribution of aviation to the UTLS BC mass budget is of limited importance. This result is similar to the findings of the model study by Kjellström et al. (1999) for aviation sulfur emissions. Kjellström et al. (1999) demonstrated that the fraction of the UTLS sulfate mass loading resulting from air traffic typical of 1991/1992 probably is very small, even in the most frequented flight regions $\left(<1 \%\right.$ north of $\left.40^{\circ} \mathrm{N}\right)$.
Vertical distributions of zonal mean total and aviationinduced BC mass concentration are displayed in Fig. 7. The zonal means of the simulated total BC mass concentrations range from more than $100 \mathrm{ng} / \mathrm{m}^{3}$ in the boundary layer at low latitudes and northern midlatitudes to values on the order of $1 \mathrm{ng} / \mathrm{m}^{3}$ in the UTLS and the lower and middle troposphere at southern mid- and high latitudes. A distinct seasonal cycle of UTLS BC is simulated for the northern midlatitudes showing the largest concentrations during summer when convective upward transport from the boundary layer is most efficient. The contribution of $\mathrm{BC}$ from aviation is largest at northern midlatitudes where the zonal mean aviation contribution ranges from up to $0.1 \mathrm{ng} / \mathrm{m}^{3}$ in the lower troposphere to values around $0.01-0.05 \mathrm{ng} / \mathrm{m}^{3}$ in the UTLS. The vertical distributions reveal that the relative aircraft-induced $\mathrm{BC}$ perturbation is largest in the UTLS. Despite that mass concentrations of $\mathrm{BC}$ from aircraft are largest in the lower troposphere, the aviation-induced perturbation is very small compared to the large lower tropospheric BC loading resulting from other sources.

Annual averages of the zonal mean aircraft-induced BC perturbations simulated in the BASE and the NOICE experiments are presented in Figs. $8 \mathrm{~b}$ and d. The BASE 
experiment shows distinct differences to the corresponding results of the previous studies by Danilin et al. (1998) and Rahmes et al. (1998)(see also Sect. 1). In the BASE experiment, the aviation-induced $\mathrm{BC}$ perturbations amount to $0.01-0.05 \mathrm{ng} / \mathrm{m}^{3}$ in the northern hemispheric UTLS. The corresponding BC perturbations derived by Danilin et al. (1998) from aircraft fuel tracer simulations with a previous version of the ECHAM GCM assuming a constant emission index of $0.04 \mathrm{~g}(\mathrm{BC}) / \mathrm{kg}$ (fuel) range between 0.05 and $0.2 \mathrm{ng} / \mathrm{m}^{3}$. The smaller values obtained in the present study are mainly attributed to changes in the $\mathrm{BC}$ emission indices as well as to the different representation of $\mathrm{BC}$ removal. In the present study, the emissions index decreases from $0.08 \mathrm{~g}(\mathrm{BC}) / \mathrm{kg}$ (fuel) at the surface to values between 0.02 and $0.03 \mathrm{~g}(\mathrm{BC}) / \mathrm{kg}$ (fuel) in the main flight altitudes (Sect. 2.3; Fig. 1). Since the aviation fuel consumption assumed by Danilin et al. (1998) is similar to that assumed here, the differences in the $\mathrm{BC}$ emission indices lead to less efficient UTLS BC emissions in the present study. In contrast to the BASE simulation performed here, removal of trace constituents by precipitation was neglected by Danilin et al. (1998) above the $400 \mathrm{hPa}$ level. At these altitudes, precipitation occurs mainly due to the sedimentation of ice crystals. The NOICE simulation demonstrates that neglecting the scavenging of $\mathrm{BC}$ by ice above $400 \mathrm{hPa}$ increases the aviation-induced $\mathrm{BC}$ perturbation by more than a factor of 2 (Figs. 8b and d).

Hence the adoption of updated emission indices as well as the inclusion of in-situ BC removal by precipitation largely explain the differences in the aviation-induced $\mathrm{BC}$ perturbations occurring between the BASE experiment and the ECHAM simulation discussed by Danilin et al. (1998). Differences in the transport characteristics of ECHAM version 3 used by Danilin et al. (1998) and ECHAM version 4 which was employed here appear to be of secondary importance for the dispersion of subsonic aircraft emissions (Rogers et al., 2002).

Nevertheless, the ECHAM results presented in the Danilin et al. (1998) model intercomparison show differences to the results of some other participating models. Since tracer removal was handled identically in the models, these discrepancies are mainly caused by different tracer transport characteristics. The maximum fuel tracer concentrations simulated by Danilin et al. (1998), which were generally obtained in the main flight levels, vary by a factor of 10 between the different model approaches. The largest maximum perturbations were simulated by some of the 2-D models. The maximum fuel tracer concentrations which correspond to the aircraft BC concentrations obtained in the 2-D model study by Rahmes et al. (1998) are also in the upper range of the values simulated by Danilin et al. (1998). ECHAM is among the models showing comparatively small concentrations. Nevertheless, the differences documented by Danilin et al. (1998) stay within a factor of 2 when the fuel tracer amount is integrated over the northern hemispheric UTLS. The variation further decreases to less than 1.5 when the results of the 2-D models are not taken into account. This reveals that differences in the models transport characteristics can cause large local differences in the simulated concentrations but that the large-scale features of the simulated aviation fuel tracer distributions are much less sensitive.

It can be concluded that the relative contribution of aviation to the UTLS BC budget suggested by the simulations performed here is only small. The simulated large-scale contribution does not exceed a few percent, even in the most frequented flight areas. The absolute aviation-induced BC perturbation simulated here is smaller than suggested by previous studies. This is mainly due to the consideration of updated $\mathrm{BC}$ emission indices as well as the inclusion of precipitation scavenging of $\mathrm{BC}$ within ice clouds. These modifications reduce the aircraft-induced UTLS BC perturbations obtained in the present simulations for the northern hemispheric UTLS by factors of about $2-5$. Without these changes, the simulations are consistent with previous simulations (Danilin et al., 1998). The model intercomparison by Danilin et al. (1998) suggests that potential changes in the transport characteristics of the model may increase the aircraft-induced perturbations locally but would not cause large changes of the integral effect. The model intercomparison by Rogers et al. (2002) reveals that increasing the vertical resolution of the model would change the results only slightly.

The UTLS concentrations of BC from surface sources simulated by other global models mostly are larger than those obtained here (Sect. 3.2.3). This suggests that the relative impact of aviation on the UTLS BC budget, if simulated with these models, could be even smaller than obtained here. However, such investigations were not performed yet with these models. Only Köhler et al. (2001) provided a consistent simulation of $\mathrm{BC}$ from aviation and surface sources. The relative contributions of aviation to the UTLS BC budget obtained by Köhler et al. (2001) (generally $<1 \%$ ) are smaller than suggested by the simulations performed in the present study.

The simulations performed here reveal that $\mathrm{BC}$ scavenging by ice is of high relevance for the UTLS BC budget. Although measurements by Ström and Ohlsson (1998) suggest that significant amounts of BC from aircraft are incorporated into ice crystals and, therefore, can be removed from the UTLS via ice sedimentation, the scavenging efficiency of $\mathrm{BC}$ by ice crystals is still uncertain. However, our simulations demonstrate that varying the assumptions on the removal efficiency of $\mathrm{BC}$ by ice sedimentation has a similar effect on the concentrations of BC from aircraft and from surface sources (Fig. 8). Hence, the relative contribution of aviation to the UTLS BC budget simulated here appears to be not very sensitive to the assumptions on $\mathrm{BC}$ removal in ice clouds. 


\section{$\mathrm{BC}$ particle number (BASE), $250 \mathrm{hPa}$ DJF \\ JJA}

a)

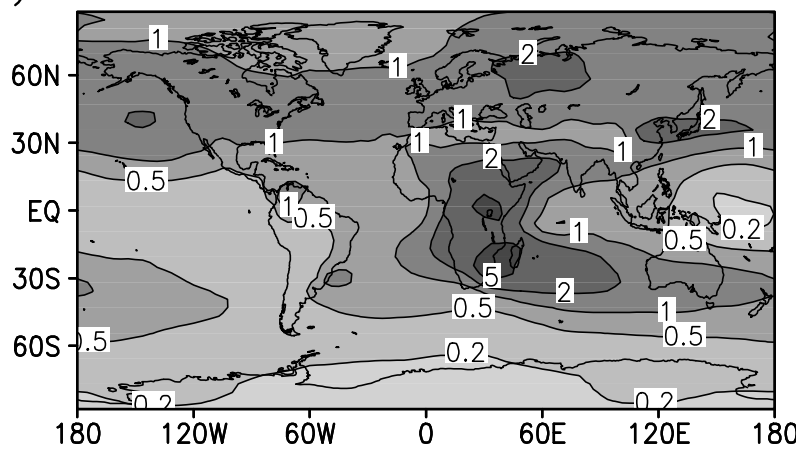

C) $\quad N(B C)$, from aircraft, maximum

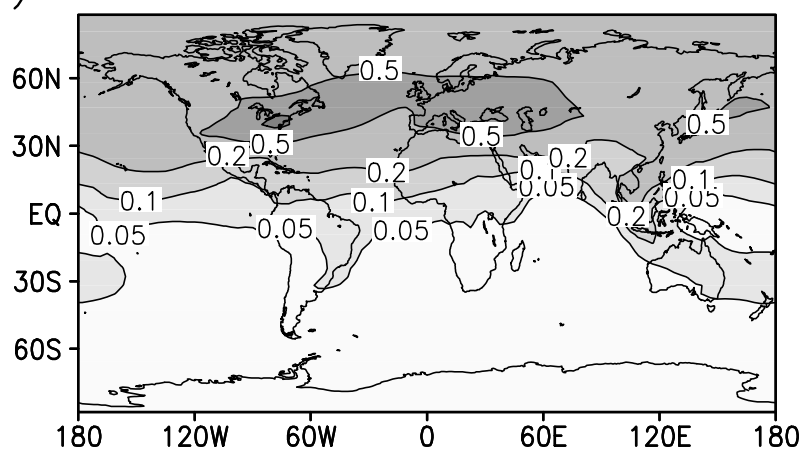

e) $\quad N(B C)$, from aircraft, minimum

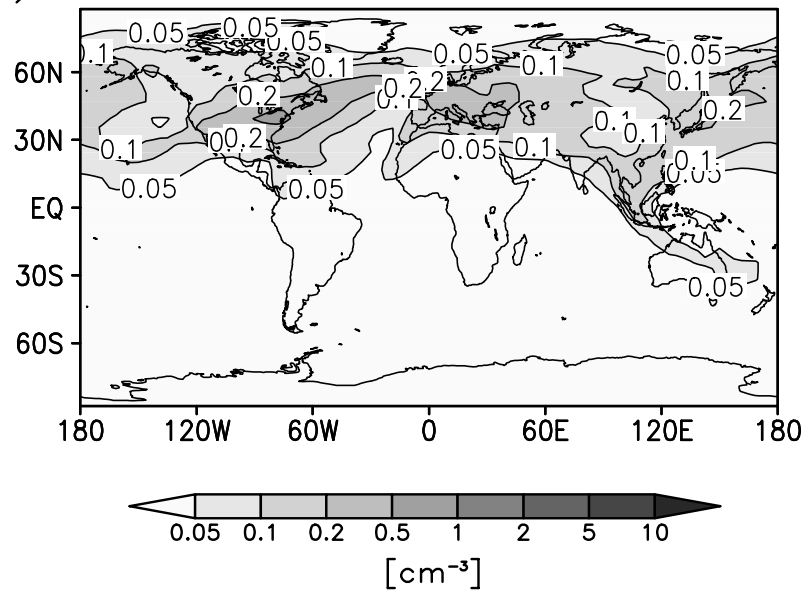

b) $\quad N(B C)$, from surface sources

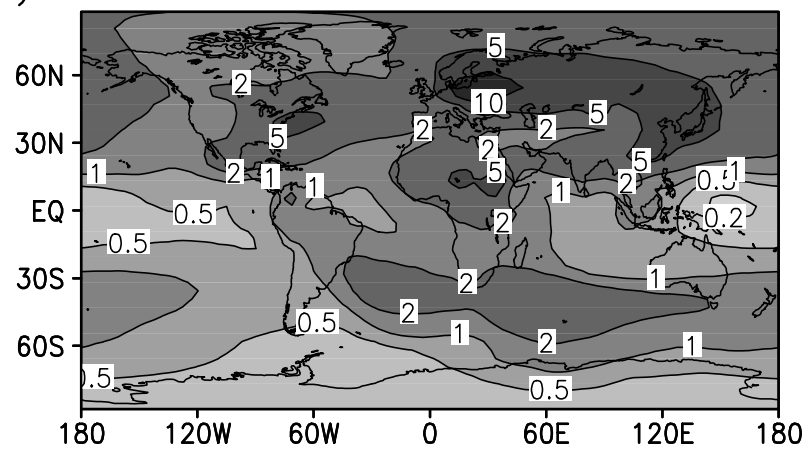

d) $\quad N(B C)$, from aircraft, maximum

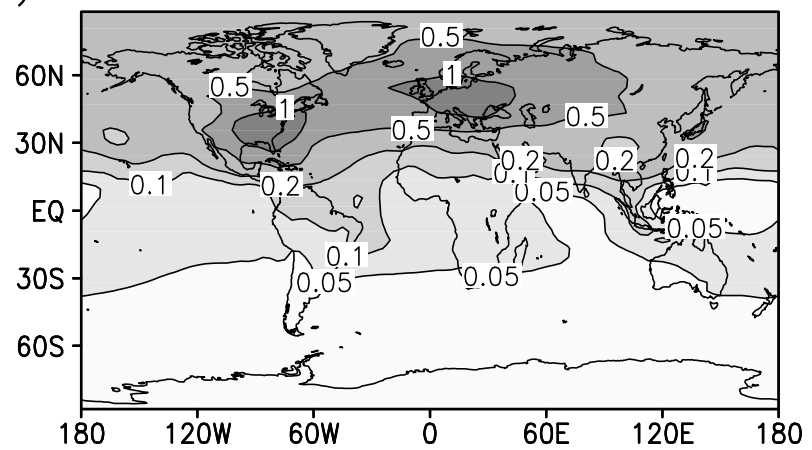

f)

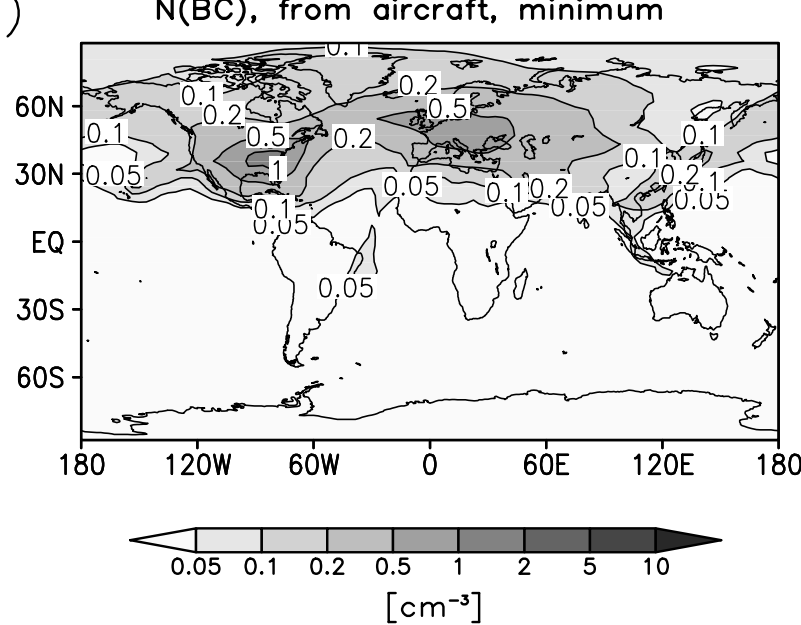

Fig. 9. Particle number concentrations $\left(\mathrm{cm}^{-3}\right.$ ) of $\mathrm{BC}$ at $250 \mathrm{hPa}$ (main aircraft flight level) during $\mathrm{NH}$ winter (left) and summer (right) simulated in the BASE experiment. (a, b): Number concentrations of BC particles resulting from surface sources. (c-f): Number concentrations of aviation-induced BC particles obtained when ageing of aviation BC (see Sect. 2.5.3) is neglected (c, d) and when efficient ageing of aviation $\mathrm{BC}$ is considered (e, f). The displayed concentrations represent 4-year averages of the December to February and the June to August periods, respectively. 


\section{$\mathrm{N}$ (aircraft-induced $\mathrm{BC}) / \mathrm{N}($ total $\mathrm{BC})(\mathrm{BASE}), 250 \mathrm{hPa}$ \\ DJF}
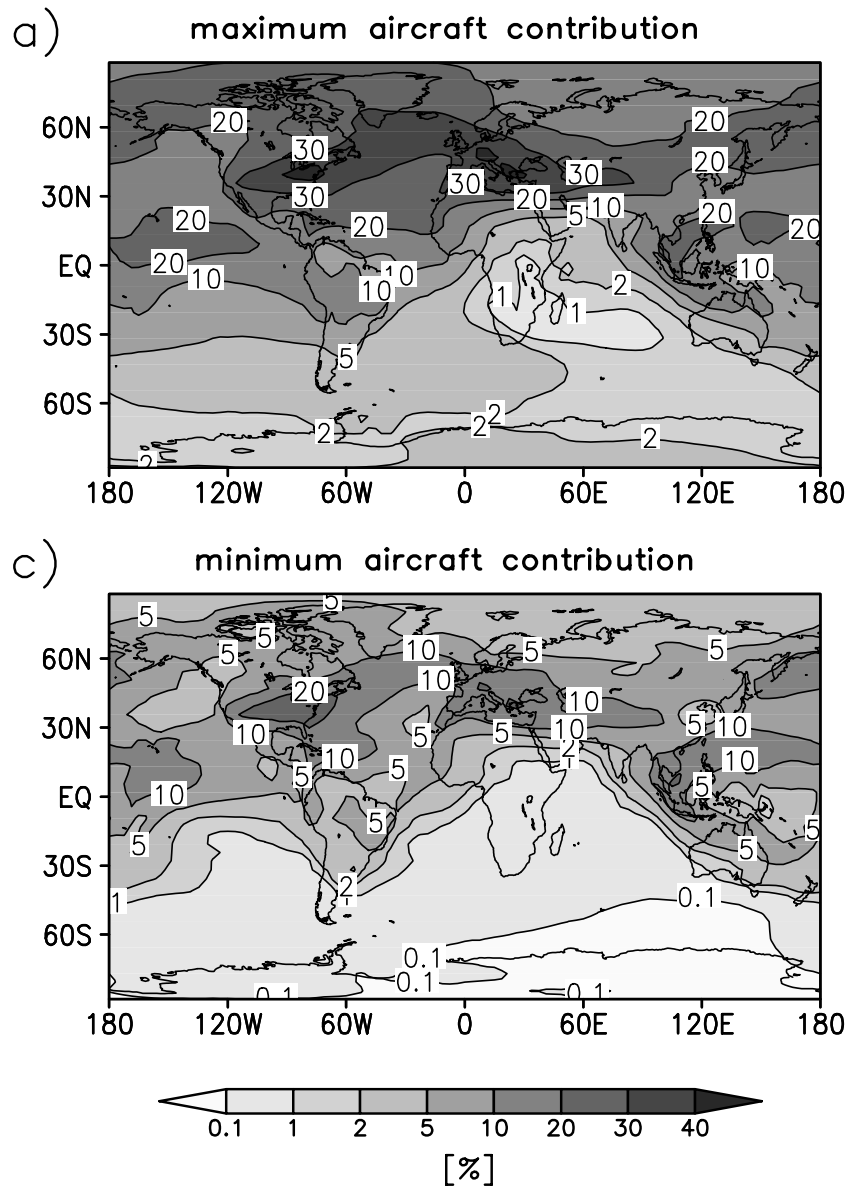

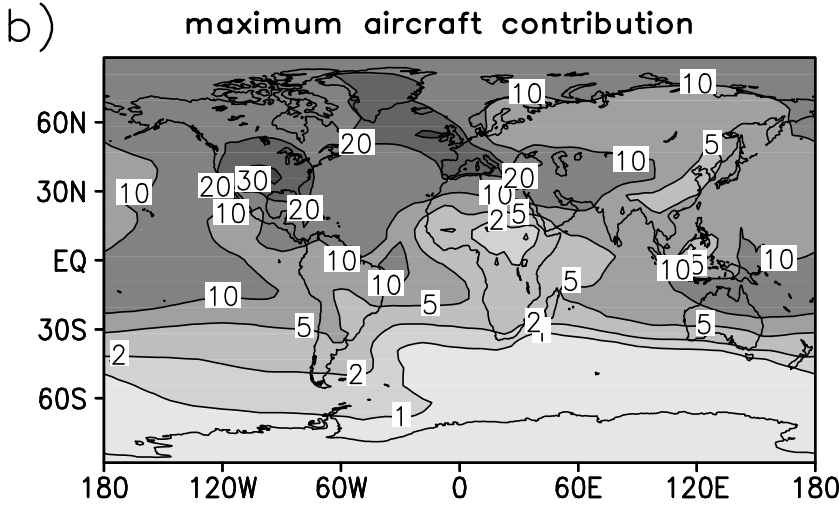

d) minimum aircraft contribution

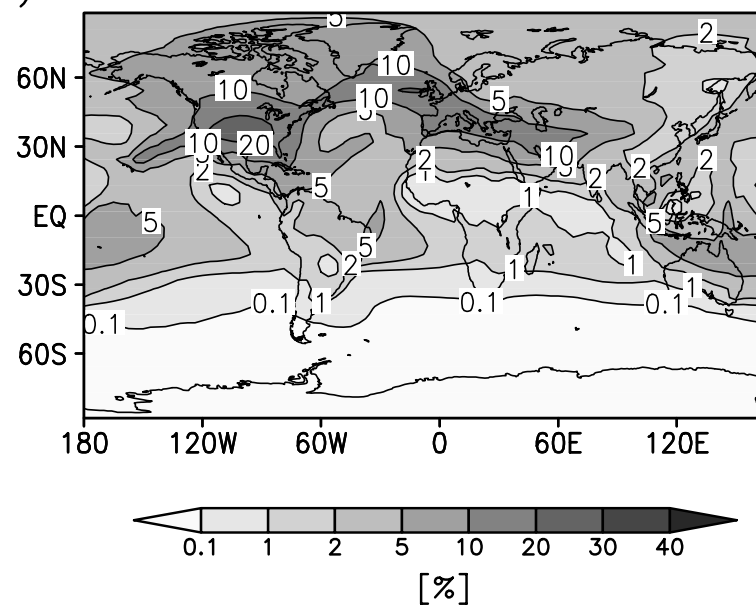

Fig. 10. Relative contribution (\%) of BC from aviation to the total $\mathrm{BC}$ particle number concentration at $250 \mathrm{hPa}$ (main aircraft flight level) during NH winter (left) and summer (right) simulated in the BASE experiment. (a, b): Ageing of aviation BC (see Sect. 2.5.3) is neglected. $(\mathbf{c}, \mathbf{d})$ : Efficient ageing of aviation BC is considered. The displayed contributions represent 4-year averages of the December to February and the June to August periods, respectively.

\subsubsection{BC particle number concentration}

Given the small aircraft-related perturbations of the $\mathrm{BC}$ mass concentration simulated here, the question should be addressed whether a larger perturbation of the $\mathrm{BC}$ particle number concentration can be expected. Figure 9 highlights the $\mathrm{BC}$ particle number concentrations simulated for the $250 \mathrm{hPa}$ level in the BASE experiment for winter and summer conditions. The spatial variation in number concentration of $\mathrm{BC}$ particles from surface sources (Figs. 9a and b) is very similar to the corresponding variation of total $\mathrm{BC}$ mass concentration (Figs. 4a and b). This is due to the constant numberto-mass ratio assumed for $\mathrm{BC}$ originating from the surface (Sect. 2.2). The number concentration of surface-related BC particles simulated for $250 \mathrm{hPa}$ typically ranges between 0.2 and $10 \mathrm{~cm}^{-3}$ and generally exceeds $1 \mathrm{~cm}^{-3}$ at northern midlatitudes.

Number concentrations of aircraft-induced BC particles simulated for $250 \mathrm{hPa}$ are highlighted in Figs. 9c-f. When the large number-to-mass ratios typical of fresh aircraft exhaust $\mathrm{BC}$ (Sect. 2.3) are generally considered for BC from aircraft, a maximum potential contribution of aviation to the number concentration of UTLS BC particles can be estimated (Sect. 2.5.2). As displayed in Figs. 9c and d, these maximum estimated particle number concentrations range between about 0.2 and $1 \mathrm{~cm}^{-3}$ at northern midlatitudes and mostly exceed $0.5 \mathrm{~cm}^{-3}$ in the most frequented flight regions over North America, the North Atlantic, and Europe.

Relating these maximum estimates for the number concentration of $\mathrm{BC}$ from aviation to the number concentrations 


\section{BC particle number (BASE), vertical distribution}
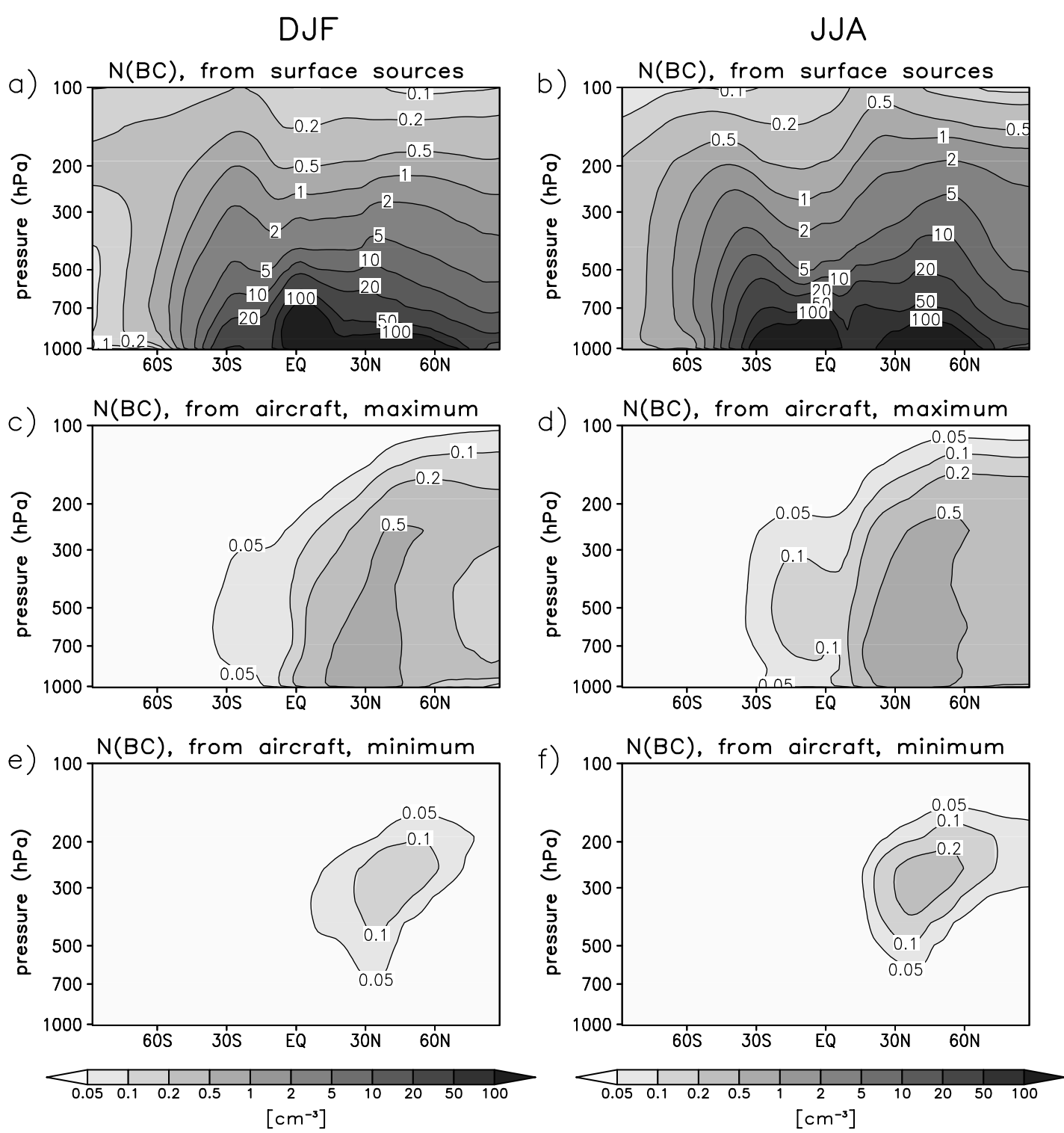

Fig. 11. As Fig. 9, but vertical distributions of zonal mean BC particle number concentrations $\left(\mathrm{cm}^{-3}\right)$ are highlighted.

obtained for surface-related $\mathrm{BC}$ particles, a maximum estimate for the relative contribution of $\mathrm{BC}$ from aviation to the total BC number concentration can be provided. During winter (Fig. 10a), the maximum estimated aviation contribution amounts to more than $20 \%$ over large parts of the northern hemisphere. The largest contributions range up to $40 \%$ and are simulated for the main flight areas. Even during summer (Fig. 10b), when the background BC burden is largest, maximum estimated contributions of $10-30 \%$ are obtained for the northern hemisphere. As in the case of the BC mass concentrations, the perturbations simulated for spring and autumn (not shown) fit smoothly into the seasonal cycle suggested above. In large parts of the most frequented flight areas, the maximum estimated aircraft-induced perturbations are larger than the inter-annual variability of the number concentration of surface-related BC particles (standard deviations of around $0.1-1$ particles $/ \mathrm{cm}^{3}$ in the 10-year BASE simulation). Hence, the simulations indicate a high potential of aviation to induce significant increases in the UTLS BC particle number concentration. If $\mathrm{BC}$ particles from aircraft can serve as heterogeneous ice nuclei, this might have important implications for the formation of cirrus clouds (e.g. Jensen and Toon, 1997; Kärcher and Lohmann, 2003; Lohmann et al., 2004).

As discussed in Sect. 2.5.3, a minimum estimate of the number concentration of $\mathrm{BC}$ from aircraft was performed considering the major ageing processes of $\mathrm{BC}$ from aviation and assuming the ageing to be very efficient. The results presented in Figs. 9e, f, 10c, and d reveal that even this 
minimum particle number concentration would make a relevant contribution to the total UTLS BC particle number concentration. The minimum estimated aircraft contribution at $250 \mathrm{hPa}$ frequently exceeds $10 \%$ in the northern hemisphere and amounts up to $20 \%$ in the main frequented flight areas.

Corresponding to the results shown in Fig. 9, vertical distributions of the zonal mean particle number concentration of $\mathrm{BC}$ emitted at the surface as well as of $\mathrm{BC}$ resulting from aviation are displayed in Fig. 11. As in the case of mass concentration, the vertical distributions indicate that the relative aircraft-induced perturbation of the $\mathrm{BC}$ particle number concentration is largest in the UTLS. In the lower and middle troposphere, the aviation-induced contribution is small compared to the large numbers of $\mathrm{BC}$ particles originating from the surface.

In comparing the estimates of number concentrations of $\mathrm{BC}$ particles originating from aviation and from surface sources, we recall that a constant number-to-mass ratio is assumed for BC particles originating from the surface. As described in Sect. 2.2, this number-to-mass ratio is derived from the assumption that the surface-related BC particles contain $n=10$ spherically shaped primary particles on average. The morphologies of $\mathrm{BC}$ particles collected in the tropopause region (Blake and Kato, 1995; Pueschel et al., 2000) and the lower stratosphere (Strawa et al., 1999) reveal that much larger agglomerates can reside at these altitudes. Hence, the average $n$ may be larger than assumed. If these large BC particles mainly originate from surface sources, the number concentrations of the surface-related BC particles could be lower than simulated here. Consequently, the relative impact of aviation on the UTLS BC particle number would be larger than estimated above. However, it is not clear whether the BC morphologies supplied by the limited number of measurements are representative of UTLS BC. Furthermore, the origin (aviation or surface) of the observed BC particles is not known. Due to a lack of observational data on the UTLS BC particle number concentration, a validation of the simulated $\mathrm{BC}$ particle numbers is currently impossible.

\section{Conclusions}

Simulations with the ECHAM4 GCM were performed to assess the global BC budget. The special focus was to quantify the impact of aviation on the global UTLS BC mass and particle number loading. The main findings resulting from these simulations are:

1. The BC mass concentrations simulated for the UTLS typically range between 0.1 and $10 \mathrm{ng} / \mathrm{m}^{3}$ and mostly exceed $1 \mathrm{ng} / \mathrm{m}^{3}$ in the northern midlatitude UTLS. A good agreement with recent observational data on UTLS BC mass loading taken over the North Atlantic and the Arctic Sea (Baumgardner et al., 2003, 2004) was found. The model is capable of reproducing the spatial variation of UTLS BC concentrations observed at different locations of the globe in earlier measurements by Blake and Kato (1995). Nevertheless, the large uncertainty of these measurements hampers a detailed evaluation of the model quality.

2. The UTLS BC mass loading induced by aircraft typically ranges between 0.01 and $0.1 \mathrm{ng} / \mathrm{m}^{3}$ at northern midlatitudes where the aviation impact is largest. Hence the contribution of aircraft to the total BC mass loading simulated here for the UTLS is small. The relative large-scale contribution does not exceed a few percent, even in areas highly frequented by aircraft.

3. The number concentrations of $\mathrm{BC}$ particles derived from the UTLS BC mass loading originating from surface sources typically range between 0.1 and $10 \mathrm{~cm}^{-3}$ and frequently exceed $1 \mathrm{~cm}^{-3}$ at northern midlatitudes. Observational data suitable to perform a validation of the simulated UTLS BC particle number concentrations are urgently required.

4. The simulations suggest that the perturbations in UTLS BC particle number concentrations resulting from aircraft are larger than the corresponding perturbations of the $\mathrm{BC}$ mass loading, mainly caused by the small sizes of aircraft-generated BC particles. Large-scale number concentrations of UTLS BC resulting from aircraft of more than $0.5 \mathrm{~cm}^{-3}$ are simulated for the main flight areas when BC particle number-to-mass ratios typical of fresh aircraft exhaust are considered. This corresponds to an aviation contribution to the total $\mathrm{BC}$ particle number concentration ranging between 10 and $40 \%$. Even when an efficient ageing of the aircraft particle exhaust is taken into account which leads to a reduction of the $\mathrm{BC}$ particle number-to-mass ratio, the aviation contribution still amounts to $10-20 \%$ in the main flight areas. Hence the simulations indicate a large potential of aviation to induce significant perturbations in UTLS BC particle number concentration.

5. Large-scale impacts of aviation on the BC mass and particle number concentrations are very small in the lower troposphere.

In the light of these findings, we evaluate the potential climatic impacts of $\mathrm{BC}$ emissions from aviation as follows:

Direct climatic impacts: A first estimate of the direct impact of BC from aviation on the atmospheric radiation budget was provided by IPCC (1999). The direct radiative forcing attributed to the aviation-induced $\mathrm{BC}$ increase was estimated to be very small. A global mean forcing of only $+0.003(+0.001$ to +0.006$) \mathrm{W} / \mathrm{m}^{2}$ was calculated considering the emissions of the 1992 fleet. The aviation-induced BC perturbation assumed in these calculations was significantly larger than the BC increase simulated in the present study. 
Hence, we suggest that the direct impact of $\mathrm{BC}$ from aviation is even smaller than the IPCC (1999) estimates.

Indirect climatic impacts: It is currently debated whether $\mathrm{BC}$ from aviation may perturb the frequency or the microphysical and optical properties of cirrus clouds via heterogeneous ice nucleation on aviation-induced $\mathrm{BC}$ particles. The simulations performed here confirm that aviation has the potential to increase the atmospheric abundance of heterogeneous ice nuclei, provided that $\mathrm{BC}$ particles from aviation nucleate ice efficiently. The number concentrations of $\mathrm{BC}$ particles from aviation simulated here are large enough to cause significant changes in cirrus ice crystal number concentration and related changes in cirrus optical properties (Gierens, 2003; Haag et al., 2003; Kärcher and Lohmann, 2003). Therefore, more detailed knowledge about the role of heterogeneous nucleation in cirrus cloud formation as well as about the ice nucleating efficiency of different BC types and other atmospheric aerosols should be gained in the future. Regarding the rapid growth rates of aviation fuel consumption projected for the future (3\% per year until 2015; IPCC, 1999), the potential indirect impact of BC from aviation may become of increasing importance in the future. Hence, further studies should consider indirect climatic impacts of BC from aircraft.

The present study further reveals some important requirements for future refinements in global atmospheric BC simulations: i) The BC loading simulated for the UTLS strongly depends on the cloud scavenging efficiency of BC. The knowledge about the hygroscopic properties of atmospheric $\mathrm{BC}$ particles currently is very sparse. Hence extensive laboratory and field measurements of $\mathrm{BC}$ hygroscopicity are required. ii) As suggested by the aviation impact simulated here, anthropogenic perturbations of the atmospheric BC particle number concentrations can be very different from the corresponding perturbations of the $\mathrm{BC}$ mass loading. Therefore atmospheric aerosol models generally should include explicit predictions of aerosol particle number concentrations, rather than employing prescribed aerosol size distributions. iii) There is a lack of observations of the UTLS BC particle mass and number concentration. Much more such observational data are required to validate global aerosol models.

Acknowledgements. We thank V. Grewe, A. Lauer and M. Ponater for helpful discussions of the ECHAM4 simulations. This research was supported by the "Helmholtz Gemeinschaft Deutscher Forschungszentren" (HGF) through the project "Particles and Cirrus Clouds" (PAZI-2). The U.S. Office of Naval research funded the development of the single particle soot photometer (SP2) and the NASA Radiation Sciences Program funded the participation of the SP2 in the SOLVE II research program. The SP2 was developed by Droplet Measurement Technologies by G. Kok, who was also responsible for making the measurements during SOLVE.

Edited by: K. Carslaw

\section{References}

Baumgardner, D., Kok, G., Raga, G., Diskin, G., and Sachse, G.: Black carbon measurements in the arctic UT/LS, Proceedings of the European Aerosol Conference 2003, J. Aerosol Sci., 979980, 2003.

Baumgardner, D., Kok, G., and Raga, G.: Warming of the arctic lower stratosphere by light absorbing particles, Geophys. Res. Lett., 31, L06117, doi:10.1029/2003GL018883, 2004.

Blake, D. F. and Kato, K.: Latitudinal distribution of black carbon soot in the upper troposphere and lower stratosphere, J. Geophys. Res., 100, 7195-7202, 1995.

Brinkop, S. and Sausen, R.: A finite difference approximation for convective transports which maintains positive tracer concentrations, Beitr. Phys. Atmos., 3, 245-248, 1997.

Chung, S. H. and Seinfeld, J. H.: Global distribution and climate forcing of carbonaceous aerosols, J. Geophys. Res., 107, (D19), 4407, doi:10.1029/2001JD001397, 2002.

Cooke, W. F. and Wilson, J. J. N.: A global black carbon aerosol model, J. Geophys. Res., 101, 19395-19409, 1996.

Cooke, W. F., Liousse, C., Cachier, H., and Feichter, J.: Construction of a $1^{\circ} \times 1^{\circ}$ fossil fuel emission data set for carbonaceous aerosol and implementation and radiative impact in the ECHAM4 model, J. Geophys. Res., 104, 22 137-22 162, 1999.

Cooke, W. F., Ramaswamy, V., and Kasibhatla, P.: A general circulation model study of the global carbonaceous aerosol distribution, J. Geophys. Res., 107, (D16), doi:10.1029/2001JD001274, 2002.

Danilin, M. Y., Fahey, D. W., Schumann, U., Prather, M. J., Penner, J. E., Ko, M. K. W., Weisenstein, D. K., Jackman, C. H., Pitari, G., Köhler, I., Sausen, R., Weaver, C. J., Douglass, A. R., Connell, P. S., Kinnison, D. E., Dentener, F. J., Fleming, E. L., Berntsen, T. K., Isaksen, I. S. A., Haywood, J. M., and Kärcher, B.: Aviation fuel tracer simulation: Model intercomparison and implications, Geophys. Res. Lett., 25, 3947-3950, 1998.

DeMott, P. J., Rogers, D. C., and Kreidenweis, S. M.: The susceptibility of ice formation in upper tropospheric clouds to insoluble aerosol components, J. Geophys. Res., 102, 19575-19584, 1997.

Dibb, J. E., Talbot, R. W., and Loomis, M. B.: Tropospheric sulfate distribution during SUCCESS: Contribution from jet exhaust and surface sources, Geophys. Res. Lett., 25, 1375-1378, 1998.

Dibb, J. E., Talbot, R. W., and Scheuer, E. M.: Composition and distribution of aerosols over the North Atlantic during the Subsonic Assessment Ozone and Nitrogen Oxide Experiment (SONEX), J. Geophys. Res., 105, 3709-3717, 2000.

Döpelheuer, A.: Berechnung der Produkte unvollständiger Verbrennung aus Luftfahrttriebwerken, Inst. für Antriebstechnik, Deutsches Zentrum für Luft- und Raumfahrt, IB-325-09-97, Cologne, Germany, 1997.

Döpelheuer, A.: Anwendungsorientierte Verfahren zur Bestimmung von $\mathrm{CO}, \mathrm{HC}$ und Ruß aus Luftfahrttriebwerken, Ph.D. thesis, Deutsches Zentrum für Luft- und Raumfahrt, Report 200210, ISSN 1434-8454, Cologne, Germany, 109, 2002.

Feichter, J., Kjellström, E., Rodhe, H., Dentener, F., Lelieveld, J., and Roelofs, G.-J.: Simulation of the tropospheric sulfur cycle in a global climate model, Atmos. Environ., 30, 1693-1707, 1996.

Fuchs, N. A.: The Mechanics of Aerosols, Pergamon, 1964.

Gierens, K.: On the transition between heterogeneous and homogeneous freezing, Atmos. Chem. Phys., 3, 437-446, 2003. 
Gierens, K., Schumann, U., Helten, M., Smit, H., and Wang, P.-H.: Ice-supersaturated regions and subvisible cirrus in the northern midlatitude upper troposphere, J. Geophys. Res., 105, 22743 22 753, 2000

Haag, W., Kärcher, B., Ström, J., Minikin, A., Lohmann, U., Ovarlez, J., and Stohl, A.: Freezing thresholds and cirrus cloud formation mechanisms inferred from in situ measurements of relative humidity, Atmos. Chem. Phys., 3, 1791-1806, 2003.

Haywood, J. M. and Ramaswamy, V.: Global sensitivity studies of the direct radiative forcing due to anthropogenic sulfate and black carbon aerosols, J. Geophys. Res., 103, 6043-6058, 1998.

Hess, M., Köpke, P., and Schult, I.: Optical properties of aerosols and clouds: The software package OPAC, Bull. Americ. Met. Soc., 79, 831-844, 1998.

Hitzenberger, R., Berner, A., Giebl, H., Drobesch, K., KasperGiebl, A., Loeflund, M., Urban, H., and Puxbaum, H.: Black carbon (BC) in alpine aerosols and cloud water - concentrations and scavenging efficiencies, Atmos. Environ., 35, 5135-5141, 2001.

Intergovernmental Panel on Climate Change (IPCC): Aviation and the Global Atmosphere, edited by: Penner, J. E., Lister, D. H., Griggs, D. J., Dokken, D. J., and McFarland, M., Cambridge Univ. Press, New York, 1999.

Jacobson, M. Z.: Control of fossil-fuel particulate black carbon and organic matter, possibly the most effective method of slowing global warming, J. Geophys. Res., 107, 4410, doi:10.1029/2001JD001376, 2002.

Jensen, E. J. and Toon, O. B.: The potential impact of soot particles from aircraft exhaust on cirrus clouds, Geophys. Res. Lett., 24, 249-252, 1997.

Kärcher, B.: Aviation-produced aerosols and contrails, Surv. Geophys., 20, 113-167, 1999.

Kärcher, B. and Meilinger, S. K.: Perturbation of the aerosol layer by aviation-produced aerosols: A parametrization of plume processes, Geophys. Res. Lett., 25, 4465-4468, 1998.

Kärcher, B. and Lohmann, U.: A parameterization of cirrus cloud formation: Heterogeneous freezing, J. Geophys. Res., 108, 4402, doi:10.1029/2002JD003220, 2003.

Kjellström, E., Feichter, J., Sausen, R., and Hein, R.: The contribution of aircraft emissions to the atmospheric sulfur budget, Atmos. Environ., 33, 3455-3465, 1999.

Koch, D.: Transport and direct radiative forcing of carbonaceous and sulfate aerosols in the GISS GCM, J. Geophys. Res., 106, 20311-20332, 2001.

Köhler, I., Dameris, M., Ackermann, I., and Hass, H.: Contribution of road traffic emissions to the atmospheric black carbon burden in the mid-1990s, J. Geophys. Res., 106, 17 997-18 014, 2001.

Köpke, P., Hess, M., Schult, I., and Shettle, E. P.: Global aerosol data set, Tech. Rep. 243, Max-Planck-Inst. für Meteorol., Hamburg Germany, 44, 1997.

Liousse, C., Penner, J. E., Chuang, C., Walton, J. J., Eddleman, H., and Cachier, H.: A global three-dimensional model study of carbonaceous aerosols, J. Geophys. Res., 101, 19411-19432, 1996.

Lohmann, U. and Kärcher, B.: First interactive simulations of cirrus clouds formed by homogeneous freezing in the ECHAM GCM, J. Geophys. Res., 107, 4105, doi:10.1029/2001JD000767, 2002.

Lohmann, U. and Roeckner, E.: Design and performance of a new cloud microphysical scheme developed for the ECHAM general circulation model, Clim. Dyn., 12, 557-572, 1996.

Lohmann, U., Feichter, J., Chuang, C. C., and Penner, J. E.: Prediction of the number of cloud droplets in the ECHAM GCM, J. Geophys. Res., 104, 9169-9198, 1999.

Lohmann, U., Feichter, J., Penner, J. E., and Leaitch, W. R.: Indirect effect of sulfate and carbonaceous aerosols: A mechanistic treatment, J. Geophys. Res., 105, 12 193-12 206, 2000.

Lohmann, U., Kärcher, B., and Hendricks, J.: Sensitivity studies of cirrus clouds formed by heterogeneous freezing in the ECHAM GCM, J. Geophys. Res., 109, D16204, doi:10.1029/2003JD004443, 2004.

Maricq, M. M., Chase, R. E., Podsiadlik, D. H., and Vogt, R.: Vehicle exhaust particle size distributions: a comparison of tailpipe and dilution tunnel measurements, SAE Technical Paper 199901-1461, SAE, 1999.

Matta, E., Facchini, M. C., Decesari, S., Mircea, M., Cavalli, F., Fuzzi, S., Putaud, J.-P., and Dell'Acqua, A.: Mass closure on the chemical species in size-segregated atmospheric aerosol collected in an urban area of the Po Valley, Italy, Atmos. Chem. Phys., 3, 623-637, 2003.

Minikin, A., Petzold, A., Ström, J., Krejci, R., Seifert, M., van Velthoven, P., Schlager, H., and Schumann, U.: Aircraft observations of the upper tropospheric fine particle aerosol in the Northern and Southern Hemispheres at midlatitudes, Geophys. Res. Lett., 30, 1503, doi:10.1029/2002GL016458, 2003.

Myhre, G., Stordal, F., Restad, K., and Isaksen, I. S. A.: Estimation of the direct radiative forcing due to sulfate and soot aerosols, Tellus, 50B, 463-477, 1998

Neusüß, C., Pelzing, M., Plewka, A., and Herrmann, H.: A new analytical approach for size-resolved speciation of organic compounds in atmospheric aerosol particles: Methods and first results, J. Geophys. Res., 105, 4513-4527, 2000a.

Neusüß, C., Weise, D., Birmili, W., Wex, H., Wiedensohler, A., and Covert, D. S.: Size-segregated chemical, gravimetric and number distribution-derived mass closure of the aerosol in Sagres, Portugal during ACE-2, Tellus, 52B, 169-184, 2000b.

Neusüß, C., Wex, H., Birmili, W., Wiedensohler, A., Koziar, C., Busch, B., Brüggemann, E., Gnauck, T., Ebert, M., and Covert, D. S.: Characterization and parameterization of atmospheric particle number-, mass-, and chemical-size distributions in central Europe during LACE 98 and MINT, J. Geophys. Res., 107, 8127 , doi:10.1029/2001JD000514, 2002.

Penner, J. E., Eddleman, H., and Novakov, T.: Towards the development of a global inventory for black carbon emissions, Atmos. Environ., 27, 1277-1295, 1993.

Penner, J. E., Chuang, C. C., and Grant, K.: Climate forcing by carbonaceous and sulfate aerosols, Clim. Dyn., 14, 839-851, 1998.

Petzold, A., Ström, J., Ohlsson, S., and Schröder, F. P.: Elemental composition and morphology of ice crystal residual particles in cirrus clouds and contrails, Atmos. Res., 49, 21-34, 1998.

Petzold, A., Döpelheuer, A., Brock, C. A., and Schröder, F. P.: In situ observations and model calculations of black carbon emission by aircraft at cruise altitude, J. Geophys. Res., 104, 22 171$22181,1999$.

Petzold, A., Fiebig, M., Flentje, H., Keil, A., Leiterer, U., Schröder, F., Stifter, A., Wendisch, M., and Wendling, P.: Vertical variability of aerosol properties observed at a continental site during LACE 98, J. Geophys. Res., 107, (D21), 8128, doi:10.1029/2001JD001043, 2002. 
Pruppacher, H. R. and Klett, J. D.: Microphysics of Clouds and Precipitation, Kluwer Acad., Dordrecht, The Netherlands, 954, 1997.

Pueschel, R. F., Blake, D. F., Snetsinger, K. G., Hansen, A. D. A., Verma, S., and Kato, K.: Black carbon (soot) aerosol in the lower stratosphere and upper troposphere, Geophys. Res. Lett., 19, 1659-1662, 1992.

Pueschel, R. F., Verma, S., Rohatschek, H., Ferry, G. V., Boiadjieva, N., Howard, S. D., and Strawa, A. W.: Vertical transport of anthropogenic soot aerosol into the middle atmosphere, J. Geophys. Res., 105, 3727-3736, 2000.

Radke, L. F., Hegg, D. A., Lyons, J. H., Brock, C. A., Hobbs, P. V., Weiss, R., and Rasmussen, R.: Airborne measurements on smokes from biomass burning, In: Aerosols and Climate, edited by P. V. Hobbs and M. P. McCormick, A. Deepak Publishing, Hampton, VA, 411-422, 1988.

Rahmes, T. F., Omar, A. H., and Wuebbles, D. J.: Atmospheric distributions of soot particles by current and future aircraft fleets and resulting radiative forcing on climate, J. Geophys. Res., 103, 31 657-31 667, 1998.

Roeckner, E., Arpe, K., Bengtsson, L., Christoph, M., Claussen, M., Dümenil, L., Esch, M., Giorgetta, M., Schlese, U., and Schulzweida, U.: The atmospheric general circulation model ECHAM4: Model description and simulation of the present day climate, Tech. Rep., 218, Max-Planck-Inst. für Meteorol., Hamburg, Germany, 1996.

Rogers, H., Teyssedre, H., Pitari, G., Grewe, V., van Velthoven, P., and Sundet, J.: Model intercomparison of the transport of aircraft-like emissions from sub- and supersonic aircraft, Meteorol. Zeitschrift, 11, 151-159, 2002.
Schmitt, A. and Brunner, B.: Emissions from aviation and their development over time, in: Final Report on the BMBF Verbundprogramm, Schadstoffe in der Luftfahrt, edited by: Schumann, U., Chlond, A., Ebel, A., Kärcher, B., Pak, H., Schlager, H., Schmitt, A., and Wendling, P., DLR-Mitteilung 97-04, Deutsches Zentrum für Luft- und Raumfahrt, Oberpfaffenhofen and Cologne, Germany, 37-52, 1997.

Schröder, F. P., Kärcher, B., Petzold, A., Baumann, R., Busen, R., Hoell, C., and Schuman, U.: Ultrafine aerosol particles in aircraft plumes: In situ observations, Geophys. Res. Lett., 25, 27892792, 1998.

Schröder, F., Kärcher, B., Fiebig, M., and Petzold, A.: Aerosol states in the free troposphere, J. Geophys. Res., 107, (D21), 8126, doi:10.1029/2001JD000194, 2002.

Schult, I., Feichter, J., and Cooke, W.: Effect of black carbon and sulfate aerosols on the global radiation budget, J. Geophys. Res., 102, 30 107-30117, 1997.

Stephens, M., Turner, N., and Sandberg, J.: Particle identification by Laser Induced Incandescence in a solid state laser cavity, Appl. Optics, 42, 3726-3736, 2003.

Strawa, A. W., Drdla, K., Ferry, G. V., Verma, S., Pueschel, R. F., Yasuda, M., Salawitch, R. J., Gao, R. S., Howard, D. D., Bui, P. T., Loewenstein, M., Elkins, J. W., Perkins, K. K., and Cohen, R.: Carbonaceous aerosol (Soot) measured in the lower stratosphere during POLARIS and its role in stratospheric photochemistry, J. Geophys. Res., 104, 26 753-26 766, 1999.

Ström, J., and Ohlsson, S.: In-situ measurements of enhanced crystal number densities in cirrus clouds caused by aircraft exhaust, J. Geophys. Res., 103, 11 355-11 361, 1998.

Williamson, D. L. and Rasch, P. J.: Water vapor transport in the NCAR CCM2, Tellus, 46A, 34-51, 1994. 